\title{
The numerical sandbox: comparison of model results for a shortening and an extension experiment
}

\author{
SUSANNE J. H. BUITER ${ }^{1}$, ANDREY YU. BABEYKO ${ }^{2,8}$, SUSAN ELLIS ${ }^{3}$, \\ TARAS V. GERYA ${ }^{4}$, BORIS J. P. KAUS ${ }^{5}$, ANTJE KELLNER ${ }^{2}$, \\ GUIDO SCHREURS $^{6}$ \& YASUHIRO YAMADA ${ }^{7}$ \\ ${ }^{1}$ Centre for Geodynamics, Geological Survey of Norway, 7491 Trondheim, \\ Norway (e-mail: susanne.buiter@ngu.no) \\ ${ }^{2}$ GeoForschungsZentrum Potsdam, Telegrafenberg, 14473 Potsdam, Germany \\ ${ }^{3}$ Institute of Geological and Nuclear Sciences, P.O. Box 30368, Lower Hutt, New Zealand \\ ${ }^{4}$ Swiss Federal Institute of Technology, Sonneggstrasse 5, 8092 Zürich, Switzerland \\ ${ }^{5}$ Department of Earth Sciences, University of Southern California, Los Angeles, USA \\ ${ }^{6}$ Institute of Geological Sciences, University of Bern, Baltzerstrasse 1-3, \\ 3012 Bern, Switzerland \\ ${ }^{7}$ Department of Civil and Earth Resources Engineering, Kyoto University, \\ Kyoto 606-5801, Japan \\ ${ }^{8}$ Now at Institut für Meteorologie und Geophysik, \\ J.W. Goethe Universität Frankfurt, Germany
}

\begin{abstract}
We report results of a study comparing numerical models of sandbox-type experiments. Two experimental designs were examined: (1) A brittle shortening experiment in which a thrust wedge is built in material of alternating frictional strength; and (2) an extension experiment in which a weak, basal viscous layer affects normal fault localization and propagation in overlying brittle materials. Eight different numerical codes, both commercial and academic, were tested against each other. Our results show that: (1) The overall evolution of all numerical codes is broadly similar. (2) Shortening is accommodated by in-sequence forward propagation of thrusts. The surface slope of the thrust wedge is within the stable field predicted by critical taper theory. (3) Details of thrust spacing, dip angle and number of thrusts vary between different codes for the shortening experiment. (4) Shear zones initiate at the velocity discontinuity in the extension experiment. The asymmetric evolution of the models is similar for all numerical codes. (5) Resolution affects strain localization and the number of shear zones that develop in strain-softening brittle material. (6) The variability between numerical codes is greater for the shortening than the extension experiment.

Comparison to equivalent analogue experiments shows that the overall dynamic evolution of the numerical and analogue models is similar, in spite of the difficulty of achieving an exact representation of the analogue conditions with a numerical model. We find that the degree of variability between individual numerical results is about the same as between individual analogue models. Differences among and between numerical and analogue results are found in predictions of location, spacing and dip angle of shear zones. Our results show that numerical models using different solution techniques can to first order successfully reproduce structures observed in analogue sandbox experiments. The comparisons serve to highlight robust features in tectonic modelling of thrust wedges and brittle-viscous extension.
\end{abstract}

Numerical and analogue modelling methods represent two different techniques with which the evolution of geological structures, such as fold-and-thrust belts and sedimentary basins, can be investigated. The underlying assumption with both methods is that their results approximate the development of structures in the real Earth in a reasonable manner. We may then expect that the results of analogue and numerical models look similar when applied to the same 
set-up. This expectation motivated us to directly compare results of numerical models obtained with different codes and results of analogue experiments from different laboratories. The aims of our study are (1) to compare results from different numerical codes and (2) to test the similarity of numerical and analogue models, in order to help establish robust features of tectonic models on the scale of the upper crust.

The companion paper (Schreurs et al. 2006) presents the results of an analogue comparison study with ten participating modelling laboratories. Two experimental set-ups were tested: (1) a brittle convergent thrust wedge experiment and (2) a brittle-viscous extension experiment. The reproducibility of modelling results between the laboratories was found to be fairly high as shown by the same general trends in the results. Differences between the analogue models were found in, for example, number of faults, fault spacing and dip, and surface slopes. The study highlights the importance of (1) a careful determination of properties of the granular material and (2) the effect of lateral side boundaries on resulting structures due to friction between model materials and sidewalls. A sandbox needs to be wide enough, therefore, to avoid such boundary effects, and structures should if possible be studied in sections well away from the sidewalls.

We present numerical equivalents of the two analogue experiments of Schreurs et al. (2006). The conditions of the analogue modelling apparatus and the analogue material properties are approached as closely as possible. We compare the numerical results to each other through determination of their qualitative (visual) and quantitative (measurements of, for example, surface slope and shear zone dip) similarities and differences. Our study is not a numerical benchmark in its strictest sense as this would require the use of the exact same initial setup, material properties, boundary conditions, mesh size and time step size (see for example the numerical convection benchmarks of Blanckenbach et al. 1989; van Keken et al. 1997). Instead, we show the variability in results obtained by using different solution methods (finite element method, finite difference method and distinct element method) and allowing variations in mesh and time step size and boundary conditions (e.g., implementation of boundary friction). With our approach, we test the code-independence of tectonic structures predicted by numerical models and our findings are, therefore, of direct relevance for studies in which numerical experiments are used to investigate geological processes. Eight numerical codes were used in our comparison: Abaqus/Standard, LAPEX-2D, I2ELVIS, Microfem, NISA/Static, PFC ${ }^{2 \mathrm{D}}$, SloMo and Sopale. A description of these codes is given in the next section.

The combination of our study with the accompanying paper results in a series of numerical and analogue model experiments, which are compared in a qualitative and quantitative manner with each other. Our results can be used to evaluate how closely various numerical solution methods can reproduce analogue model conditions. Issues that should be considered carefully in the 'numerical sandbox' include the suitability of continuum methods (e.g., finite element method) in simulating the behaviour of discontinuous grains, the importance of dilation and compaction in granular materials, and the representation of velocity discontinuities. Numerical modelling of sandbox experiments poses significant computational challenges requiring that numerical codes are able to (1) calculate large deformations, (2) represent complex boundary conditions, including frictional boundaries and free surfaces, and (3) include a complex rheology involving both viscous and frictional/plastic materials. These challenges reflect directly the state-of-the-art requirements for numerical modelling of largescale tectonic processes.

The two experimental set-ups were designed to reflect set-ups commonly used in the study of upper-crustal tectonic processes. Convergent thrust wedges have been studied with analytical techniques (Davis et al. 1983; Dahlen 1984), analogue experiments (e.g., Mulugeta 1988; Gutscher et al. 1998a; Storti et al. 2000) and numerical models (e.g., Strayer et al. 2001; Burbridge \& Braun 2002). Similarly, brittleviscous extension has been investigated with analogue (e.g., Michon \& Merle 2000; Bahroudi et al. 2003) and numerical (e.g., Behn et al. 2002; Wijns et al. 2003) methods. A few previous studies have combined numerical and analogue modelling methods for studying a tectonic process on the scale of the crust. Sassi et al. (1993) investigated the reactivation of preexisting faults in a compressive regime and showed how the visualization of the stress field in the numerical results (obtained with a distinct element method) could help in the interpretation of the observed reactivation of some low angle faults. The models calculated with the distinct element method by Saltzer \& Pollard (1992) of structures in sedimentary layers overlying basement normal faults show a high resemblance to deformation patterns typically observed in sandbox models. A high level of agreement between analogue and numerical models of 
brittle and brittle-viscous thrust wedges was obtained by Ellis et al. (2004). Their results indicate that the continuum approximation of the finite element method does not necessarily need to be a strong limitation in modelling granular materials. An encouraging agreement between results from finite element and analogue models is also shown by Panien et al. (2006); Cruden et al. (2006) and Le Pourhiet et al. (2006).

Numerical and analogue modelling techniques share the advantages and disadvantages of trying to capture aspects of a geological process in a model. Both methods allow the evolution of structures to be observed, which can be helpful in generating ideas on the origin and development of structures observed in the field. With numerical and analogue models it is possible to vary model parameters easily and determine their relevance for the process under consideration. However, models are also only an approximation of the natural situation and their restrictions should be taken into account when interpreting their results. Advantages of the numerical method are the easy quantification of model results, including the possibility of tracking stresses, strain and strain-rates during the evolution of the model, and the relatively large freedom in choice of material properties (including a relatively easy implementation of temperaturedependent rheologies), boundary conditions and geometries. Some approaches lose accuracy when dealing with large deformation situations (due to remeshing, for example) or large viscosity contrasts. The resolution of 3D models is in general still quite low. Analogue models on the other hand are very suitable for studying the $3 \mathrm{D}$ evolution of structures with time. This makes it possible to evaluate the effects of, for example, lateral changes in material properties or oblique extension. The technique is limited in the application of temperature dependent rheologies, phase changes and variations in geometries. Numerical and analogue techniques are partly complementary and the combination of both methods may help establish the robustness of model results (see also Smart \& Couzens-Schultz 2001).

\section{Modelling methods}

\section{Material properties}

The models contain three materials, which have properties resembling those of quartz sand, glass microbeads and polydimethylsiloxane (PDMS). In the analogue comparison, every laboratory used its own granular materials, which typically differ in frictional properties and density (see Schreurs et al. (2006) and Table 1). In the numerical experiments fixed values are used to allow the comparison of the numerical results to each other (Table 1). The material behaviour of the numeric brittle materials is characterised by a Coulomb failure-frictional criterion:

$$
\sigma_{t}=\sigma_{n} \tan (\phi)+C
$$

where $\sigma_{t}$ denotes shear stress, $\sigma_{n}$ normal stress, $\phi$ the angle of internal friction and $C$ cohesion. Measurements of the properties of analogue granular materials show that deformation initially occurs through a combination of elastic and frictional strain-hardening behaviour until failure at peak strength $\left(\phi_{\text {peak }}\right)$, followed by a strain-softening phase until a stable strength

Table 1. Material properties

\begin{tabular}{|c|c|c|c|c|c|c|c|c|c|c|}
\hline \multirow[t]{2}{*}{ Material } & \multicolumn{5}{|c|}{$\begin{array}{l}\text { Values in numerical } \\
\text { models }\end{array}$} & \multicolumn{5}{|c|}{$\begin{array}{l}\text { Measured analogue } \\
\text { properties* }\end{array}$} \\
\hline & $\begin{array}{l}\text { Density } \\
\left(\mathrm{kg} \mathrm{m}^{-3}\right)\end{array}$ & $\begin{array}{c}\mathrm{C} \\
(\mathrm{Pa})\end{array}$ & $\phi_{\text {peak }}^{\dagger}$ & $\phi_{\text {stable }}^{\ddagger}$ & $\begin{array}{c}\eta \\
(\mathrm{Pa} \mathrm{s})\end{array}$ & $\begin{array}{l}\text { Density } \\
\left(\mathrm{kg} \mathrm{m}^{-3}\right)\end{array}$ & $\begin{array}{c}\mathrm{C} \\
(\mathrm{Pa})\end{array}$ & $\phi_{\text {peak }}^{\dagger}$ & $\phi_{\text {stable }}^{\ddagger}$ & $\begin{array}{c}\eta \\
(\mathrm{Pa} \mathrm{s})\end{array}$ \\
\hline Sand & 1560 & 10 & $36^{\circ}$ & $31^{\circ}$ & & $1350-1740$ & $3-150$ & $33^{\circ}-45^{\circ}$ & $28.2^{\circ}-39^{\circ}$ & \\
\hline Microbeads & 1480 & 10 & $22^{\circ}$ & $20^{\circ}$ & & $1400-1600$ & $-25-50$ & $21^{\circ}-29.2^{\circ}$ & $20^{\circ}-26.2^{\circ}$ & \\
\hline PDMS & 965 & & & & $5 e 4$ & 965 & & & & $5 e 4$ \\
\hline Side friction & & 0 & $19^{\circ}$ & $19^{\circ}$ & & & & $20^{\circ 8}$ & $16^{-}-17^{\circ s}$ & \\
\hline
\end{tabular}

\footnotetext{
*Values from Schreurs et al. (2006) for the materials used in the laboratories of University of Bern, IFP Rueil-Malmaison, University of Parma, University of Pavia and University of Toronto. Sand is sieved from $20 \mathrm{~cm}$ height with an approximate filling rate of 250 grams/ minute. PDMS from Weijermans (1986)

${ }^{\dagger}$ Angle of internal friction at peak strength.

*Angle of internal friction at stable strength

${ }^{\S} \mathrm{GFZ}$ sand measured by J. Lohrmann shows an angle of internal friction of $20^{\circ}$ softening to $16^{\circ}$ (fine-grained sand, $20-200 \mu \mathrm{m}$ ) or 17 (coarser sand, 20-650 $\mu \mathrm{m}$ )
} 
$\left(\phi_{\text {stable }}\right)$ is reached (Lohrmann et al. 2003; Panien 2004; see also Jaeger \& Cook 1979). Five of the eight numeric codes used in our study include elastic material behaviour. For sand, the elastic component is probably relatively small (J. Adam pers. comm.). Most of the numerical models (six of eight) have been run without dilation and (de)compaction of the materials is, therefore, not automatically taken into account. The strengthening of material in the initial strain-hardening phase seen in analogue models (Adam et al. 2005) is in these cases not included. Strain-softening from peak strength to stable strength is assumed to be caused by dilatation of sand at yield and is explicitly prescribed in the numeric models that do not include dilatation. The softening is simulated by a linear decrease in the angle of internal friction over a finite strain interval of 0.5 to 1.0 (finite strain is total accumulated effective strain as measured by the square root of the second invariant of the strain tensor). The cohesion values of the analogue materials were determined using different measuring apparatus (see Schreurs et al. 2006) and show a large variation. Cohesion is obtained by extrapolation of the shear stress versus normal stress curve and is, therefore, likely to be an overestimate at low stress values where the stress curve is no longer a straight line, but has a convex-outward shape (Ranalli 1987; Schellart 2000). The boundary friction between sand and the sidewalls and base of the model (which are covered with an 'Alkor' foil in the analogue experiments) is approximately $20^{\circ}$, softening to $16^{\circ} / 17^{\circ}$ (for fine sand with grain size $20-200 \mu \mathrm{m}$ and coarse sand with grain size 20-650 $\mu \mathrm{m}$, J. Lohrmann, pers. comm.) and a constant value of $19^{\circ}$ has been used in the numerical experiments.

PDMS is a Newtonian material with a viscosity of $5 \times 10^{4} \mathrm{~Pa} \mathrm{~s}$ (at room temperature and strain rates below $3 \times 10^{-3} \mathrm{~s}^{-1}$, Weijermars 1986) and low Maxwell times. It is modelled as a linear viscous material: $\tau=2 \eta \dot{\varepsilon}$, for deviatoric stress $\tau$, viscosity $\eta$, and strain-rate $\dot{\varepsilon}$.

\section{Scaling}

Some of the models are scaled up from the analogue sandbox-scale $(\mathrm{cm})$ to upper-crustal scale $(\mathrm{km})$. This scaling requires that dynamic similarity is observed (Hubbert 1937; see also Ellis et al. 2004). Dynamic similarity is maintained when force ratios and length ratios are constant. The models in this study can be scaled completely through the following three relationships: (1) geometric similarity:

$$
\frac{l_{n}}{l_{a}}=\text { constant }
$$

where $l_{n}$ and $l_{a}$ are the lengths in the numerical and analogue model, respectively; (2) constant ratio of gravitational force to viscous force between the numerical and the analogue model:

$$
\frac{\rho g l^{2}}{\eta v}=\text { constant }
$$

where $\rho$ density, $g$ gravitational acceleration, $\eta$ viscosity and $v$ velocity; and (3) constant ratio of frictional strength $\left(\sigma_{y}\right)$ to lithostatic pressure:

$$
\frac{\sigma_{y}}{\rho g l}=\text { constant }
$$

The values for $\rho, \phi$ and $g$ in the numerical models are within the ranges of the analogue values (Table 1).

\section{Description of the numerical codes}

In the following, only a brief description of the main features of the numerical codes is given and the reader is referred to the references provided for more detailed information. Specific assumptions concerning the boundary conditions for the experiments are discussed with the description of the model set-up for each experiment.

Abaqus/Standard. Results obtained with Abaqus/ Standard are shown for both experiments and were provided by Susan Ellis. Abaqus is a Lagrangian Finite Element code with implicit time integration (Abaqus/Standard User's Manual 2003). Material behaviour is visco-elasto-plastic and materials deform elastically until plastic or viscous yield is reached, after which deformation continues on yield. Tests for the shortening experiment show that material quickly reaches plastic yield once it enters the deforming region. Plastic yielding is modelled using a non-associative plastic flow law with dilation chosen as zero (to facilitate comparison with the other experiments). Strain softening is included. Boundary friction is implemented through an elastic-stick contact surface formulation. The experiments are scaled such that $1 \mathrm{~cm}$ equals $1 \mathrm{~km}$ in the numerical model.

I2ELVIS. Taras Gerya provided results from his I2ELVIS code (the successor of I2VIS, Gerya \& Yuen 2003) for both experiments. I2ELVIS solves the Stokes equation for creeping 
flows using the finite difference method on a Eulerian staggered grid combined with a marker-in-cell technique. Material behaviour is visco-elasto-plastic and incompressible (with, therefore, zero dilation). Elasto-plastic deformation dominates for sand-like material due to the high background viscosity of $10^{12} \mathrm{~Pa} \mathrm{~s}$, which results in a large visco-elastic relaxation time $\left(10^{6} \mathrm{~s}\right)$. In contrast viscous deformation dominates for PDMS-like material due to the low viscosity of $5 \times 10^{4} \mathrm{~Pa} \mathrm{~s}$, which gives small visco-elastic relaxation times $(0.05 \mathrm{~s})$. Strain softening is included. Boundary friction is incorporated through frictional contact layers (4 elements wide at the sides and 2.5 elements high at the base). Free surface behaviour is obtained through a low viscosity 'air' layer on top of the model $\left(\eta=1 \mathrm{Pas}\right.$ and $\left.\rho=1 \mathrm{~kg} \mathrm{~m}^{-3}\right)$. The experiments are not scaled.

LAPEX-2D. Model results for LAPEX-2D were provided by Andrey Babeyko for both experiments. LAPEX-2D solves for balances of mass, momentum and energy through an explicit Lagrangian Finite Difference technique (FLACtype) (Cundall \& Board 1988; Poliakov et al. 1993; Babeyko et al. 2002). Material and history properties including full stress and strain tensors are tracked and updated by using particles. The material behaviour is viscoelastic with plastic yielding. Dilatation is zero. Strain softening is included. Boundary friction is implemented through explicitly added frictional forces at the boundary nodes (newly added feature for these experiments). The experiments are scaled whereby $1 \mathrm{~cm}$ equals $10 \mathrm{~km}$ in the numerical model.

Microfem. Susan Ellis also provided model results calculated with Microfem (Fullsack 1995) for both experiments. Microfem is a plane-strain arbitrary Lagrangian Eulerian finite element code. The Stokes equation for incompressible creeping flows is solved on a Eulerian grid on which material properties are tracked using a Lagrangian material grid. A free surface is achieved through vertical stretch or shortening of the Eulerian grid. Material behaviour is either viscous or plastic and incompressible (zero dilatation). Strain softening is included. The version used here is modified from the original code from the Dalhousie Geodynamics group. Frictional contacts are incorporated in a simple manner by allowing nodes to move unconstrained tangential to the boundary once frictional yield is exceeded (Ellis et al. 2004). The experiments are scaled such that $1 \mathrm{~cm}$ equals $1 \mathrm{~km}$ in the numerical models.

NISA II/Static 12.0. Results for the shortening experiment were provided by Antje Kellner. NISA/Static is a Lagrangian Finite Element code (NISA II User Manual 1997). It solves the equations of mechanical equilibrium for viscoelasto-plastic materials, but was used in an elasto-plastic mode for this study. Associated Mohr-Coulomb plasticity is used with a dilatation angle equal to the angle of internal friction. Strain softening is not included. Boundary friction is implemented through the contact element tool: For each frictional boundary two contact surfaces are defined. A contact element combines two contact surfaces facing each other. The experiment is not scaled.

$P F C^{2 D}$. Results for the shortening experiment using the Distinct Element Method $\mathrm{PFC}^{2 \mathrm{D}}$ (PFC ${ }^{2 D}$ User's Guide 1999) were provided by Yasuhiro Yamada. The model domain consists of discrete circular elements where only neighbours interact. Linear elasticity (forcedisplacement law; Cundall \& Strack 1979) is incorporated through normal and shear forces at element contacts. The force in the normal direction and a pre-defined friction coefficient determine the inter-element friction in the shear direction. During deformation the size of each element is preserved and only the arrangement in the particle assembly is distorted. Dilatation is incorporated as a change in the inter-element porosity. Strain softening is not included. Boundary friction is incorporated in a similar manner as the inter-element friction. The experiments are scaled whereby $1 \mathrm{~cm}$ equals $300 \mathrm{~m}$ in the numerical model.

SloMo. Results for the extension experiment were provided by Boris Kaus. SloMo is a planestrain finite element code (Kaus 2005) which solves the Stokes equations for incompressible materials. The rheology is visco-elasto-plastic with Mohr-Coulomb plasticity. A mixed formulation is employed, with linear, discontinuous, shape-functions for pressure and quadratic shape functions for velocity to avoid spurious pressures (Pelletier et al. 1989). Uzawa-type iterations are used to satisfy the incompressibility constraint (Cuvelier et al. 1986). In this work, the code has been used in a Lagrangian fashion, with regular remeshing to deal with large deformations (see also Poliakov \& Podladchikov 1992). Iterations are performed for plasticity, to ensure that both the force balance and the plastic yield functions 
are satisfied simultaneously. The interface between sharply varying material properties is tracked by marker-chains, whereas other material properties are stored on the integration points. Strain softening is included. Dilatation is zero. The experiment is not scaled.

Sopale. Model results for Sopale are shown for both experiments and were provided by Susanne Buiter. Sopale is a plane-strain arbitrary Lagrangian Eulerian finite element code (Fullsack 1995) and is the successor of Microfem. A more efficient tracking of material properties (whereby the Lagrangian particles are no longer only constrained to a regular grid and particle injection maintains a high particle density) allows a higher resolution. This version has been modified from the original code to allow horizontal stretch or shortening of the Eulerian grid (in addition to the vertical Eulerian grid modification for free surface behaviour). Strain softening is included. Boundary friction is implemented through the use of frictional contact layers (4 elements wide at the sides and 4 elements high at the base). The experiments are scaled such that $1 \mathrm{~cm}$ scales up to $1 \mathrm{~km}$ in the numerical model.

\section{Shortening experiment}

\section{Model set-up}

The shortening experiment follows a more or less classic set-up used to study fold-and-thrust belt evolution with analogue models. Shortening is achieved by moving the right-hand wall inward while the left wall and base are held fixed. The model consists of 'sand' layers with an embedded $0.5 \mathrm{~cm}$ thick layer of weaker 'microbeads' (Fig. 1a). Total height is $3.5 \mathrm{~cm}$. The length of the models is variable (Table 2), but since deformation did not reach the left wall in any of the models, all were considered long enough. At the right side an initial wedge $10 \mathrm{~cm}$ long with $10^{\circ}$ surface slope overlies the model. This wedge slope is in the stable field for a sand wedge (as calculated for this set-up from Dahlen 1984; Zhao et al. 1986). The two main problems with representing the analogue set-up numerically lie with the boundary conditions. First, different solutions were applied to simulate boundary friction (contact boundary friction or frictional boundary layers). Second, the mobile wall moving over the base of the sandbox represents a velocity discontinuity, which may lead to high pressures in this corner.

(a) Shortening experiment
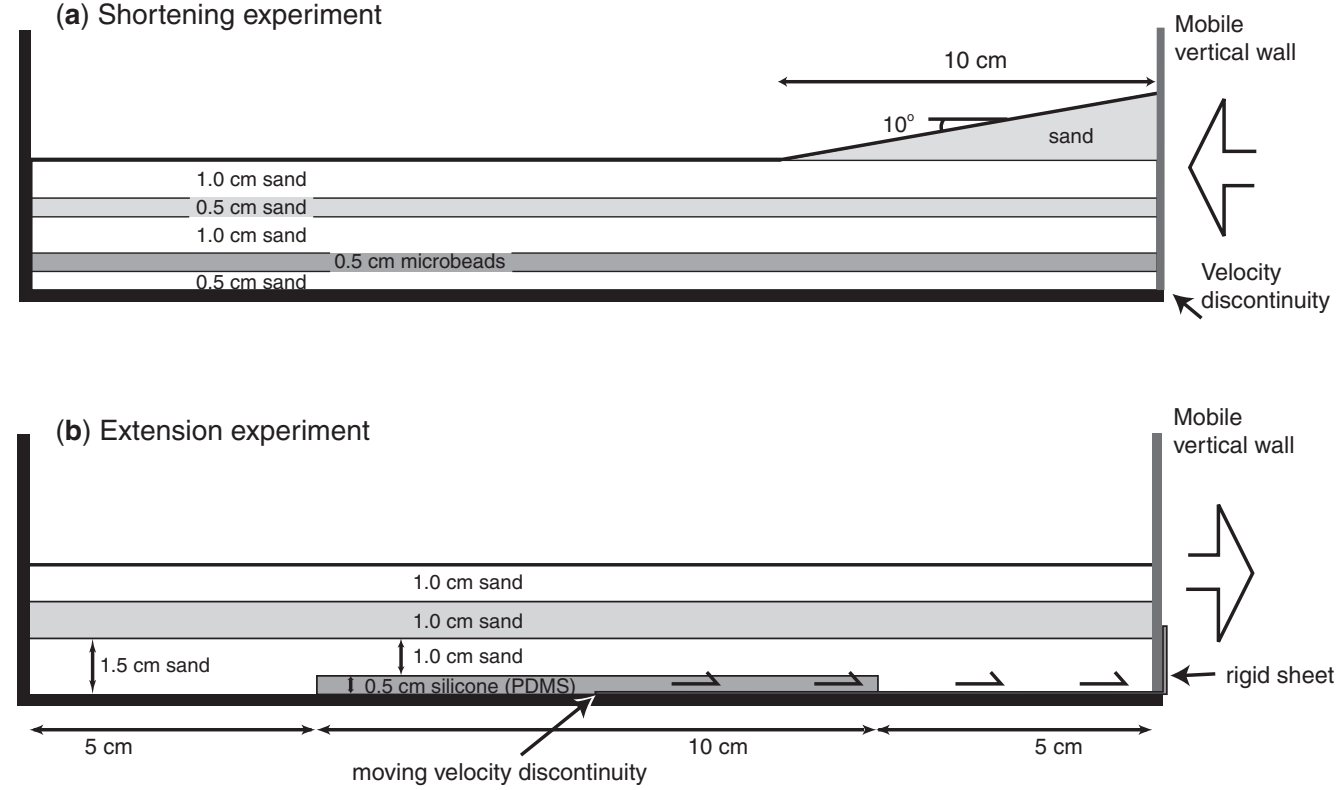

Fig. 1. (a) Set-up of the shortening experiment. Horizontal layers of 'sand' (which have the same properties and differ in colour only) with an embedded layer of weaker 'microbeads' are shortened through a mobile wall on the right-hand side which is pushed leftwards. (b) Set-up of the extension experiment. A viscous layer (PDMS, $10 \times 0.5 \mathrm{~cm}$ ) lies in the central part of the model on the base. The rest of the model consists of three 'sand' layers (only differing in colour). Extension is achieved by moving the right wall with the attached $10 \mathrm{~cm}$ long sheet outwards to the right. 
Table 2. Shortening experiments

\begin{tabular}{|c|c|c|c|c|c|c|c|c|}
\hline Code & Method* & Nodes $^{\dagger}$ & $\begin{array}{l}\text { Track } \\
\text { points }\end{array}$ & $\begin{array}{l}\text { Domain } \\
\text { length }\end{array}$ & $\begin{array}{l}\text { Norm. } \\
\text { elem. } \\
\text { size }^{\S}\end{array}$ & $\begin{array}{c}E^{\| \prime} \\
(\mathrm{MPa})\end{array}$ & $v^{1}$ & $\begin{array}{c}\eta^{2} \\
(\mathrm{~Pa} \mathrm{~s})\end{array}$ \\
\hline $\begin{array}{l}\text { Abaqus/ } \\
\text { Standard }\end{array}$ & FEM & $301 \times 36$ & n.a. & $30 \mathrm{~km} / 30 \mathrm{~cm}$ & 0.1 & 0.5 & 0.25 & $5 e 6$ \\
\hline I2ELVIS & $\mathrm{FDM}+\mathrm{MIC}$ & $900 \times 75$ & 393750 & $45 \mathrm{~cm}$ & 0.05 & 3 & 0.50 & $1 \mathrm{e} 12$ \\
\hline LAPEX-2D & $\mathrm{FDM}+\mathrm{MIC}$ & $351 \times 71$ & 400000 & $400 \mathrm{~km} / 40 \mathrm{~cm}$ & 0.075 & 0.1 & 0.125 & $4.5 \mathrm{e} 10$ \\
\hline Microfem & ALE & $201 \times 36$ & 7236 & $28 \mathrm{~km} / 28 \mathrm{~cm}$ & 0.17 & n.a. & n.a. & $4 \mathrm{e} 13^{3}$ \\
\hline NISA/Static & FEM & $201 \times 14 / 18$ & n.a. & $50 \mathrm{~cm}$ & 0.25 & $0.5-1.0^{\bullet}$ & 0.25 & n.a. \\
\hline $\mathrm{PFC}^{2 \mathrm{D}} /$ Kyoto & DEM & $\sim 18000$ & n.a. & $12 \mathrm{~km} / 40 \mathrm{~cm}$ & 0.06 & n.a. & n.a. & n.a. \\
\hline Sopale & ALE & $401 \times 71$ & 253411 & $40 \mathrm{~km} / 40 \mathrm{~cm}$ & 0.08 & n.a & n.a. & $4.6 \mathrm{e} 13$ \\
\hline
\end{tabular}

${ }^{*} \mathrm{FEM}=$ Finite Element Method, FDM = Finite Difference Method, ALE = Arbitrary Lagrangian Eulerian, DEM = Distinct Element Method, MIC = Marker-in-Cell.

${ }^{\dagger}$ Nodes in horizontal $\times$ vertical direction, or total number of nodes.

${ }^{\ddagger}$ First value is for the numerical model, second value is its equivalent scaled down to the sandbox scale. Height is 3.5 (left-hand side) to $5.26 \mathrm{~cm}$ (top of wedge at right-hand side).

${ }^{\S}$ Normalized element size is measured as the square root of element area, scaled to sandbox scale $(\mathrm{cm})$.

"Young's modulus, scaled to sandbox scale.

- $0.5 \mathrm{MPa}$ for microbeads, 1.0 MPa for sand

${ }^{1}$ Poisson ratio.

${ }^{2}$ Background viscosity, scaled to sandbox scale.

${ }^{3}$ Equivalent linear viscosity; a non-linear viscosity was used in the calculations.

The shortening experiment was run with seven numerical codes (Abaqus/Standard, I2ELVIS, LAPEX-2D, Microfem, NISA/Static, PFC ${ }^{2 \mathrm{D}}$ and Sopale). Five experiments have zero dilatation, while NISA/Static and $\mathrm{PFC}^{2 \mathrm{D}}$ are dilatational. Details of the set-up for each code are given in Table 2. The initial geometry for all numerical models is shown in Figure 2a. The following code-specific assumptions and explanations apply:

Abaqus/Standard. Because Abaqus/Standard uses a Lagrangian formulation and remeshing was not employed, the code cannot handle large deformations and fails to converge at an early step.

I2ELVIS. The rigid mobile wall (with a background viscosity of $10^{14} \mathrm{Pas}$ and a shear modulus of $10^{2}-10^{4} \mathrm{MPa}$ ) is moving inside the computational domain and is, therefore, not simulated through an external boundary condition. The right-hand side frictional boundary layer is limited in vertical extent. During shortening, part of the weak 'air' layer at the top of the model moves spontaneously to behind the mobile wall.

LAPEX-2D. Diffusive erosion (diffusion coefficient of the order $10^{-6} \mathrm{~m}^{2} \mathrm{~s}^{-1}$ ) is applied at the surface to avoid steep slope angles not supported by the current meshing technique.

Microfem. A small amount of surface smoothing is applied. Tests have shown that this does not significantly affect the dynamic evolution.
NISA II/Static. Because NISA/Static uses a Lagrangian approach without remeshing, the code cannot handle large deformations and fails to converge at an early step.

$P F C^{2 D}$. The density of all materials is $1600 \mathrm{~kg}$ $\mathrm{m}^{-3}$ and, therefore, differs slightly from the values used in the other experiments (Table 1). The radii size is randomized within $12-24 \mathrm{~m}$ (sand) and 5-10 m (microbeads). Shearing tests suggest a shear angle in bulk behaviour of $35^{\circ}$ for sand and $25^{\circ}$ for microbeads. The basal boundary condition has the same friction angle as sand and is, therefore, higher than the value used in the other experiments.

Sopale. To avoid numerical instabilities associated with an abrupt velocity change the mobile wall velocity is smoothed by extrapolating the applied velocity to 0 over the lowermost $200 \mathrm{~m}$ (equals $0.2 \mathrm{~cm}$ ) of 'sand' (excluding the basal frictional layer). A minimal amount of diffusive erosion (diffusion coefficient $10^{-9} \mathrm{~m}^{2} \mathrm{~s}^{-1}$ ) is applied at the surface.

\section{Model results}

The structural evolution of all models is shown in Figure 2 with plots of geometry and strain-rates after 2, 6, 10 and $14 \mathrm{~cm}$ of shortening (unless specified otherwise). Shear zones can readily be identified on the geometry plots, while the strain-rate plots visualize their propagation, moment of initiation and later abandonment. 


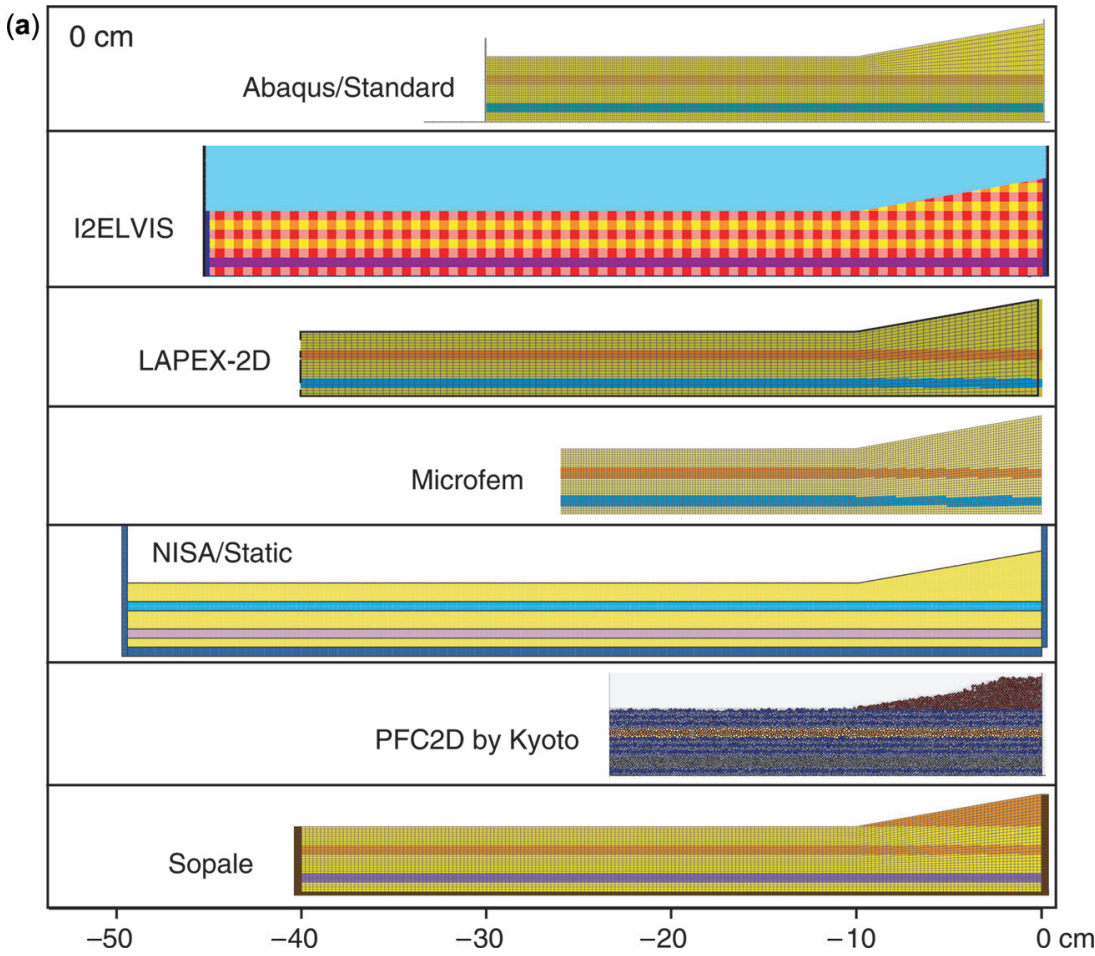

Fig. 2. Results for the shortening experiment. All quantities (including strain-rates) are scaled down to the sandbox scale. (a) Initial geometries. The grid of Abaqus/Standard is the calculation grid, while for LAPEX-2D, Microfem and Sopale the shown grid is (a subset of) the tracking grid. (b) Geometries after $2 \mathrm{~cm}$. Note that Abaqus/Standard and Microfem are shown after $1.8 \mathrm{~cm}$ and NISA/Static after $2.3 \mathrm{~cm}$. (c) Strain-rates after $2 \mathrm{~cm}$ (Abaqus/Standard and Microfem after $1.8 \mathrm{~cm}$, NISA/Static after $2.3 \mathrm{~cm}$ ). (d) Geometries after $6 \mathrm{~cm}$. (e) Strain-rates after $6 \mathrm{~cm}$. (f) Geometries after $10 \mathrm{~cm}$. (g) Strain-rates after $10 \mathrm{~cm}$. (h) Geometries after $14 \mathrm{~cm}$. (i) Strain-rates after $14 \mathrm{~cm}$.

The strain-rate plots also show when the weak embedded layer is utilized and whether shear zones propagate forward along the weak layer or along the base of the model. In continuum numerical models shear displacement is not accommodated along discrete fault planes, but rather along more distributed shear zones. For ease of comparison with the analogue models, we will, however, sometimes refer to 'faults' when describing numerical results.

In order to allow a comparison of all model results in a more quantitative manner we measured the following properties (Table 3, Figs 3 and 4): amount of displacement at which forward thrusts form, their dip angle, the spacing between thrusts, the amount of faultcontrolled shortening, surface slope, when the embedded weak layer is activated, and the length of the detachment in this layer. We found, however, that our measurements were influenced by the measurer and subject to small differences in interpretation. The values reported here were, therefore, completely measured by two people, in the same manner, and subsequently averaged. A fault was considered to be initiated when deformation had clearly localized along it as shown by strain-rate maxima and small finite displacement of the deforming material. Dip angles were measured on the finite deformation plots and represent a dip angle for the whole shear zone (not differentiating between upper and lower dip angles). The variation in dip angle values between the two measurers was on average $2^{\circ}$ (ranging between $0^{\circ}-5^{\circ}$ ). Measurements of surface slope are rather inaccurate in the initial stages of shortening when only one thrust has formed (Fig. 4b), but improve substantially as soon as a second thrust has formed (Fig. 4c). From then on the difference between the values measured by the two measurers did not exceed $3^{\circ}$. Oscillations in surface slope angles occur just before or after the formation of a new thrust, depending on the degree to which a new thrust is 
(b)

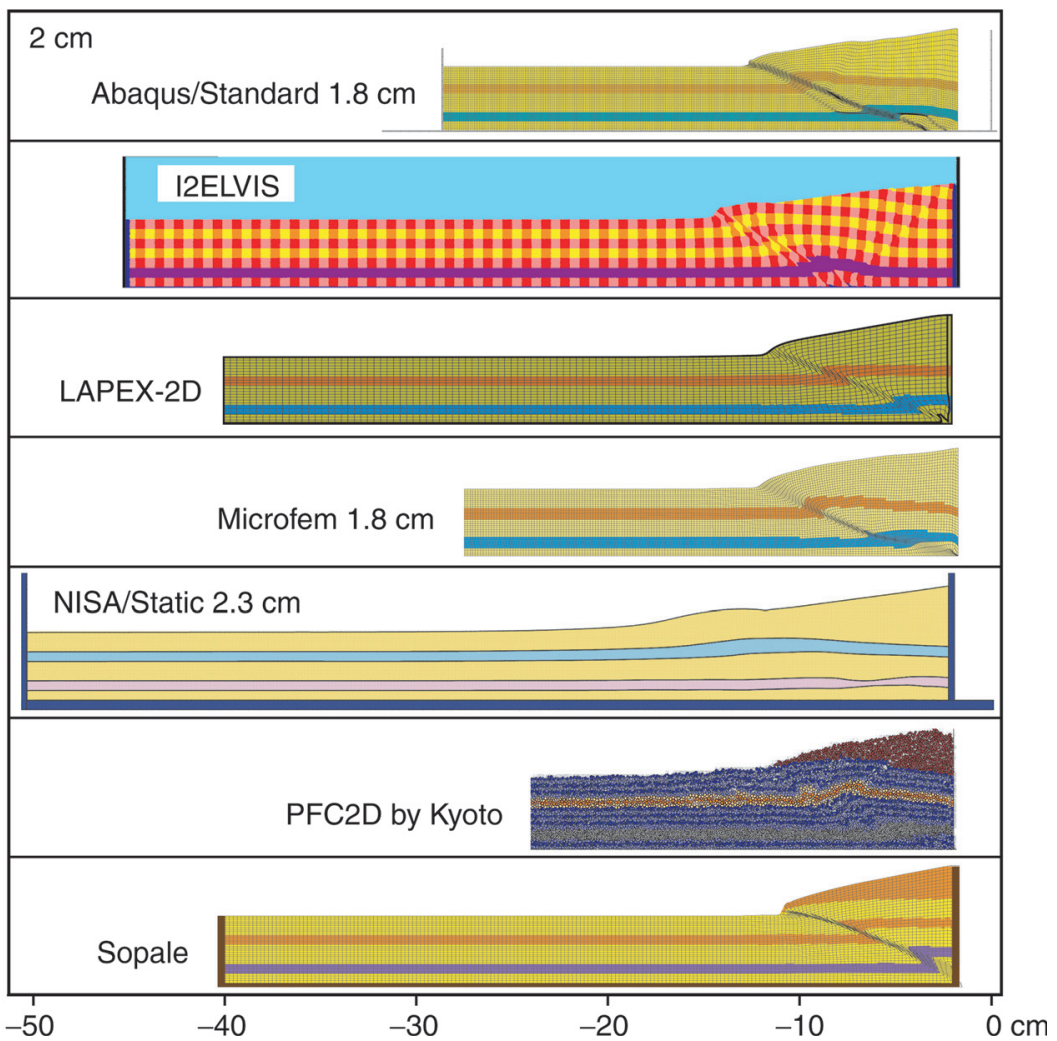

Fig. 2. Continued.

incorporated into the wedge. To determine the amount of shortening accommodated by faults, we measured the offset of layers at a fault by using the cut-off points of the layers and the fault. Folding of layers towards a fault zone was classified as folding-controlled shortening. Fault-controlled shortening was in a number of cases difficult to determine accurately as the cut-off points of layers with faults were smeared out. The ranges in Table 3 reflect the differences between the two measurers.

The numerical models share many similarities: (1) Shortening is accommodated by in-sequence forward propagation of thrusts (Figs 2 and 3a). (2) The first-formed forward thrust roots at the base of the mobile wall in most of the experiments (Figs 2b and c). (3) By $2 \mathrm{~cm}$ of displacement an active forward thrust has formed in all models (Fig. 2b). (4) The location where the first-formed forward thrust reaches the surface is influenced by the surface wedge in almost all of the experiments (except maybe NISA/Static) (Fig. 2b). (5) The embedded weak layer accommodates shear displacement in almost all experiments when sufficient shortening has occurred to increase the surface wedge (Table 3) (the strain-rate plots for I2ELVIS show activity of the weak layer, but no finite strain accumulates here). (6) The surface slope remains in the stable field for critical taper theory (calculated from Dahlen (1984) and Zhao et al. (1986) for homogeneous sand) (Fig. 4). Activation of the embedded weak layer has no discernable effect on surface slope (Table 3 and Fig. 4). The stable taper field for a cohesive wedge building in $2.5 \mathrm{~cm}$ thick material above the weak layer is almost the same as the stable field shown in Figure 4.

Although the manner in which the models accommodate shortening leads to a similar style of deformation, it is also clear from Figures 2, 3 and 4, and Table 3 that variations exist among the models. Differences between the model results are: (1) The number of thrusts that have formed at a specified amount of displacement is variable (maximum two thrusts difference in the displacement range examined here) (Figs 2 and 3a). (2) The dip angle of the 


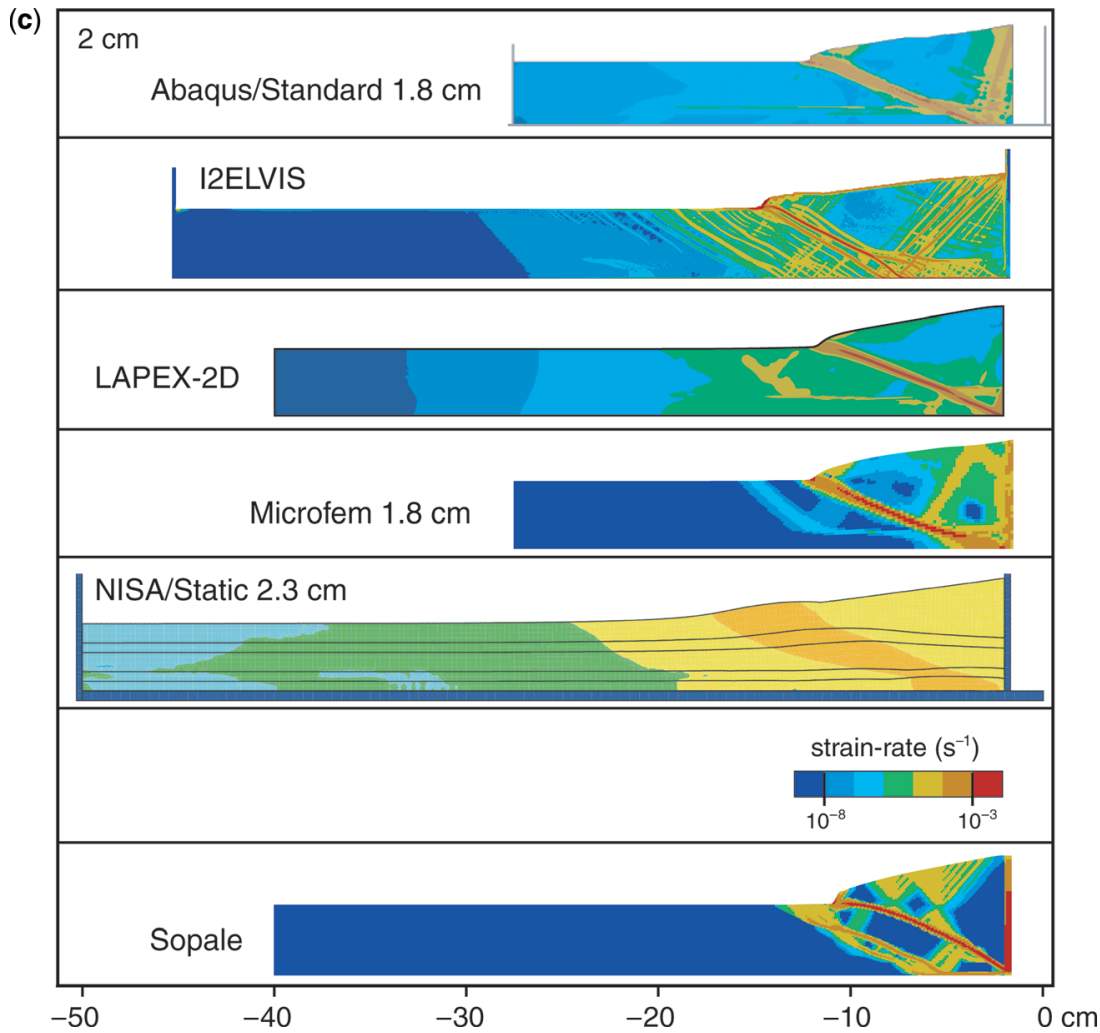

Fig. 2. Continued.

forward thrusts shows variations of up to $14^{\circ}$. The dip angle of the first thrusts is most likely influenced by the initial surface wedge. Later thrusts have dip angles between $45^{\circ}$ (non-dilatant Roscoe angle) and $45^{\circ}-\phi / 2$ (Coulomb angle) (Vermeer 1990). (3) The distance between a newly formed thrust and the previously formed thrust is highly variable (Fig. 3c). (4) The embedded weak layer is first activated at different amounts of shortening (Table 3). (5) The amount of fault controlled shortening differs highly (Table 3).

\section{Sensitivity analyses}

An important advantage of numerical models is the ease with which the sensitivity to model parameters can be investigated. We tested the variability of the numerical results to assumptions regarding the model set-up (mesh resolution and elasticity) and values of material properties (cohesion and basal friction). We found that the evolution of thrusts is influenced by the resolution of the calculation domain, which may provide a partial explanation of differences found between the numerical results. Figures 5a and $\mathrm{b}$ show the difference after $10 \mathrm{~cm}$ displacement for I2ELVIS caused by increasing the normalized element size (Table 2) from 0.05 to 0.1 , thus reducing the resolution. A higher resolution tends to increase the number of shear zones, while the individual shear zones become more focussed. A similar trend can be seen when comparing the result from the two ALE-type codes Microfem (lower resolution) and Sopale (higher resolution). Studies using analogue sandbox experiments found that thrust spacing depends on layer thickness, basal friction and surface slope (Mulugeta 1988; Mulugeta \& Koyi 1992; Gutscher et al. 1998b). However, as pointed out by Mulugeta (1988) changes in material layering may perturb a systematic thrust spacing and it may be, therefore, that the embedded weak ('microbeads') layer in our set-up partly contributes to the observed irregularity in thrust spacing. The sensitivity of shear zone width and spacing is discussed further with the results of the extension 
(d)
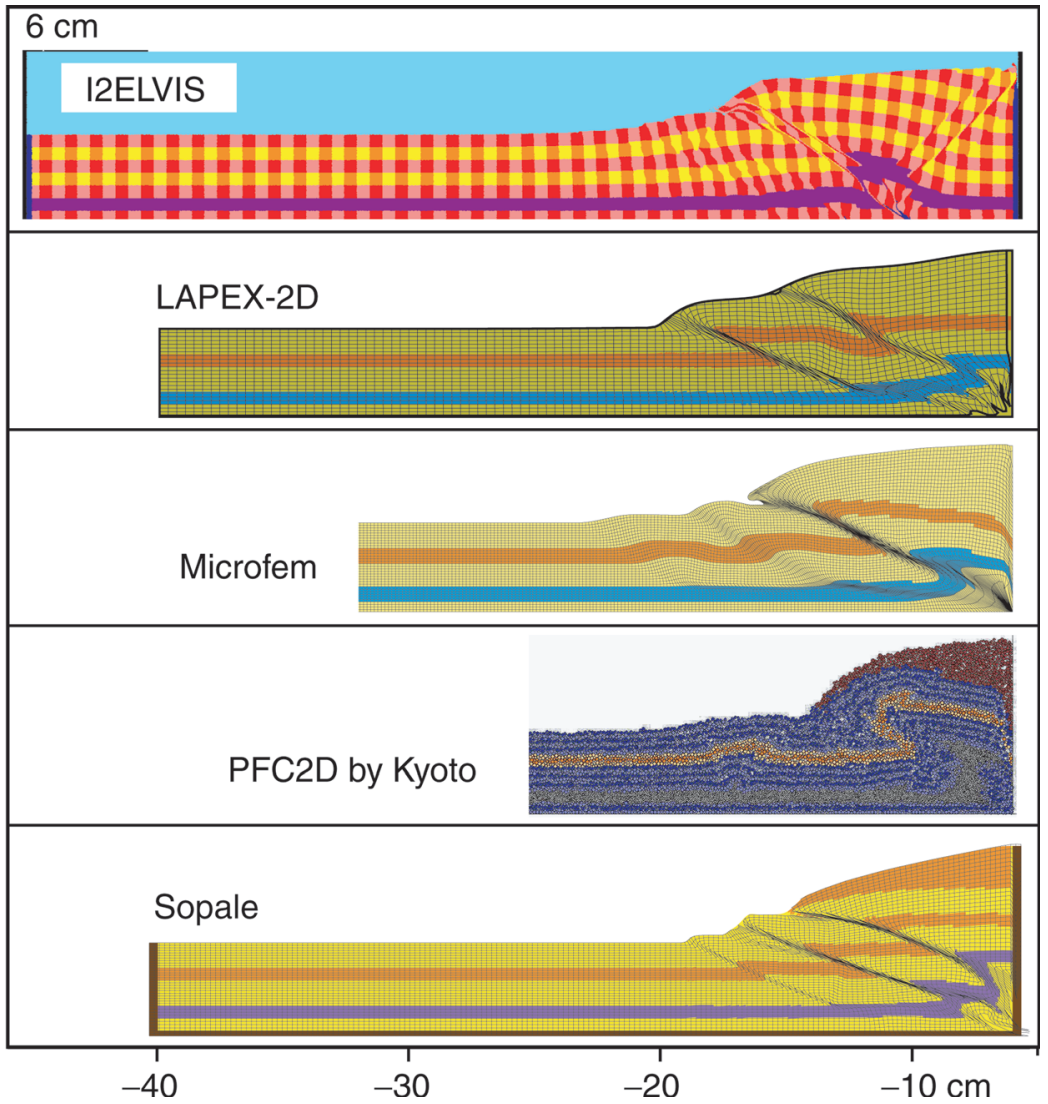

Fig. 2. Continued.

experiment (section on Localization of shear deformation).

We have assumed that in sandbox-type experiments the amount of finite strain that can be accommodated by elastic material behaviour is small. Abaqus/Standard, I2ELVIS, NISA/ Static and LAPEX-2D include elastic behaviour and their deformation is essentially elastoplastic in the shortening experiment, while Microfem and Sopale behave essentially rigidplastic. A general comparison of the largedeformation results shows that the elastic component in material behaviour may lead to slightly more distributed deformation (as strain can also be accommodated between shear zones), but that overall the effect of elasticity is small for our set-up and material properties. In LAPEX-2D, effective elastic strain remains below approximately $2 \%$.

Critical taper theory predicts that the strength of the frictional materials directly influences the taper angle that can be supported. With higher cohesion values the range of stable taper angles increases (from Zhao et al. 1986). Ellis et al. (2004) found in their thrust wedge experiments that surface slope increases with increasing cohesion, whereby the increase in surface slope mainly occurs at the toe of the material which has been thrust up. Tests with Sopale show that variations in the slope angle of the enveloping surface for cohesion variations from 0 to $100 \mathrm{~Pa}$ are limited $\left(2^{\circ}\right.$ for displacements of $10 \mathrm{~cm}$ or more) without a clear trend towards higher slopes for higher cohesion. Higher cohesion material can support steeper edges of thrust sheets (Figs 5c, d and e). As the higher cohesion value was assigned to 'sand' and 'microbeads' alike, the strength contrast across the 'microbeads' layer is reduced and less shear displacement is consequently accommodated along it.

From Sopale experiments we find that a decrease in the basal friction angle (from $19^{\circ}$ to $10^{\circ}$ ) reduces the surface slope (with around $8^{\circ}$ 
(e)

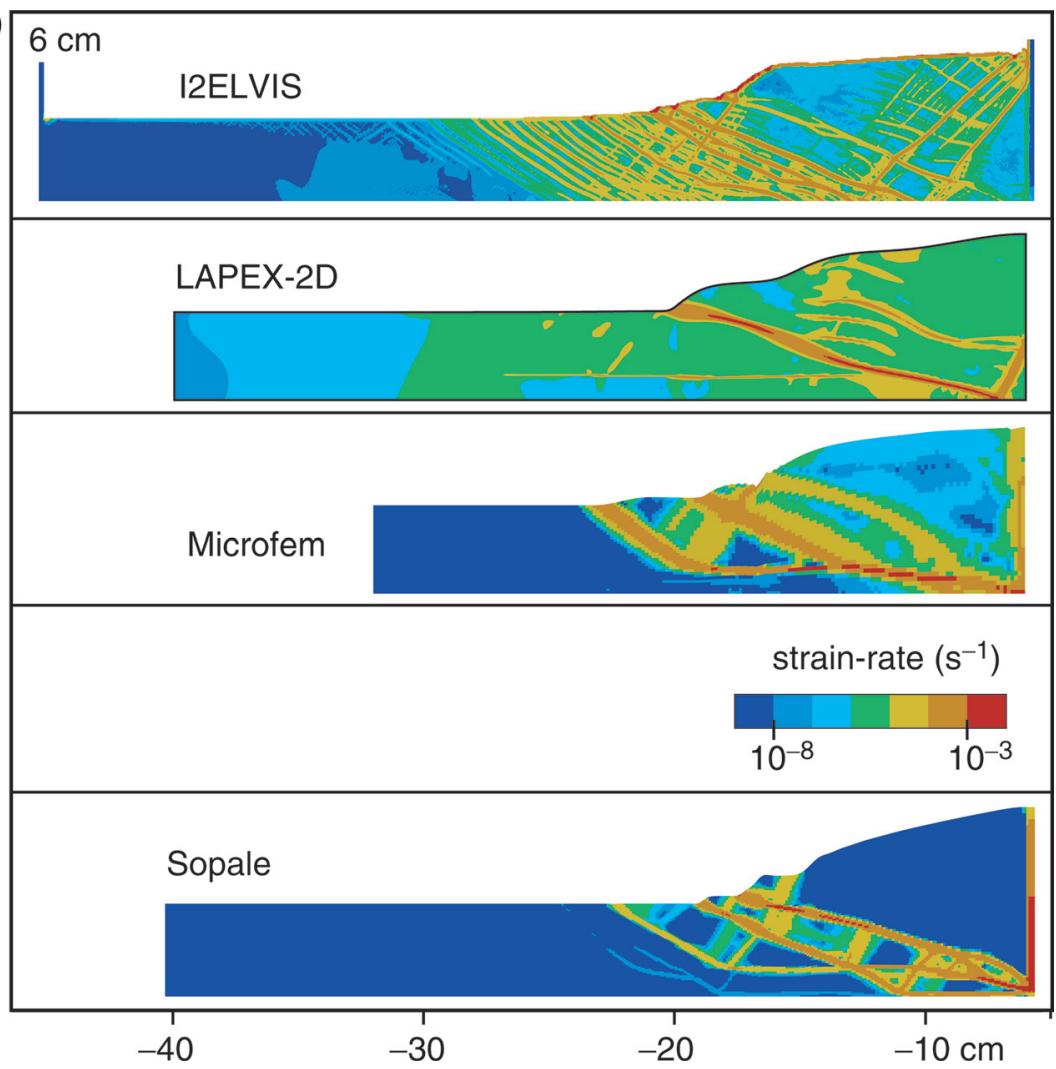

Fig. 2. Continued.

for the later shortening stages). This trend is in accordance with critical taper theory, which predicts lower critical taper angles for lower basal friction (Davis et al. 1983), and has also been found in other thrust wedge studies (Gutscher et al. 1998a; Vanbrabant et al. 1999). For low basal friction forward propagation of thrusts occurs faster.

\section{Implications of the numerical experiments}

The numerical results for the thrust wedge experiment show similar deformation styles in which shortening is accommodated in a mainly rigidplastic manner by in-sequence forward propagation of thrusts. Thrust wedge formation and propagation is, therefore, a robust feature of the seven models. However, despite the use of similar initial set-ups, material properties and boundary conditions, variability in structural evolution arises. These differences highlight the possible ranges in structural evolution and measurable quantities (e.g., surface slope) due to the application of different numerical codes, variable resolution and different implementation of boundary conditions. A fascinating unexpected result is the role of measurer bias in determining quantities such as dip and thrust spacing. Our results indicate that thrust spacing and the number of thrusts versus displacement should be considered carefully when evaluating results from numerical simulations and applying these (in a general manner) to natural systems. This implies that although numerical models may be used 'qualitatively' to interpret the mechanics of thrust wedges, limitations exist to the extent to which quantifiable measures such as thrust fault sequences may be compared at the present time. Future code comparisons may be helpful in reducing the differences between the numerical model results. Test experiments should preferably have a simplified set-up (avoiding abrupt changes in velocity boundary conditions which may require numerical smoothing), the same grid resolution, and material properties as similar as possible. 


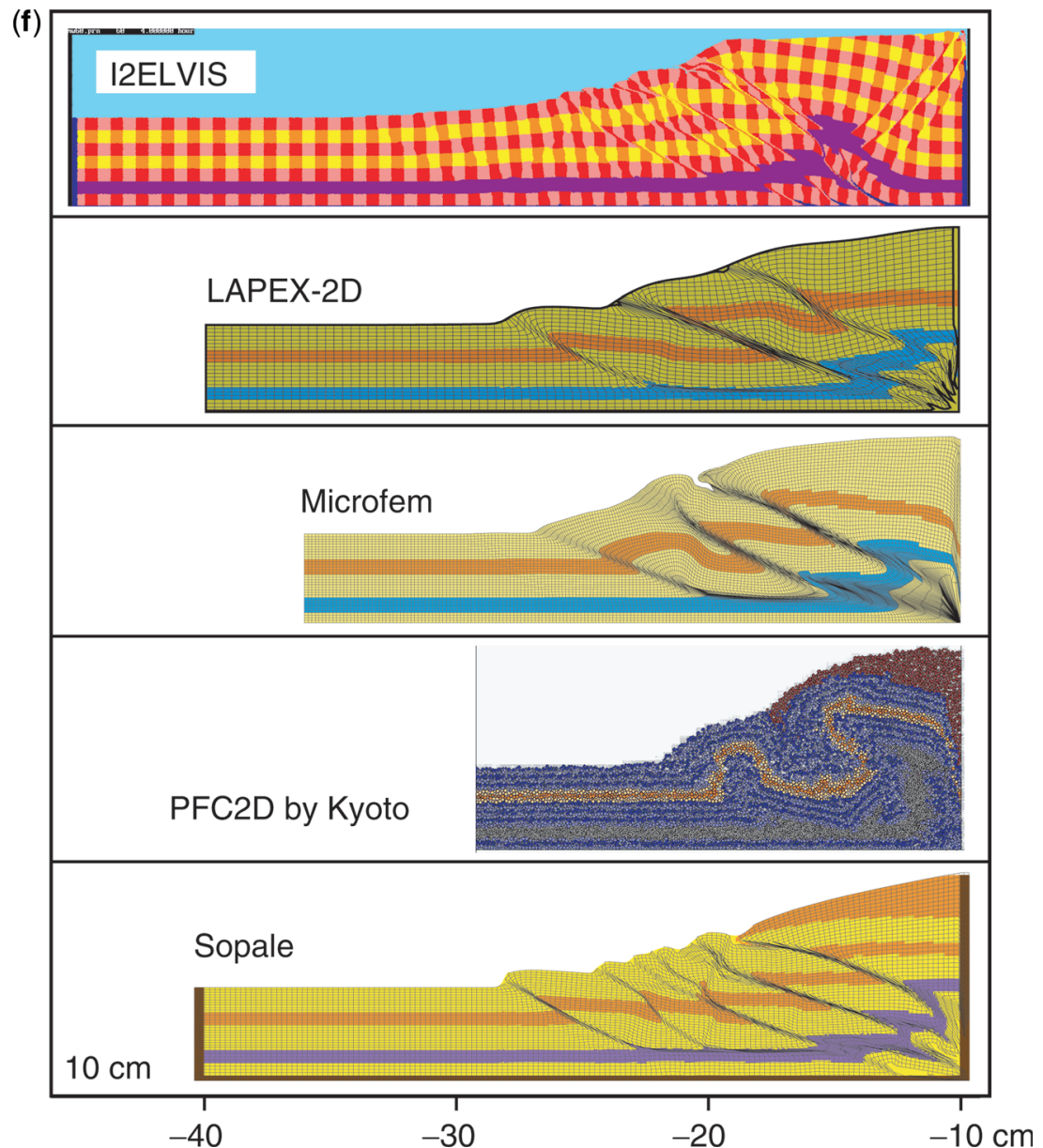

Fig. 2. Continued

\section{Comparison to analogue results}

Figure 6 compares the numerical model geometries at 2 and $14 \mathrm{~cm}$ of displacement to results at equivalent stages from the analogue experiments of the laboratories of Bern, IFP, Parma, Pavia and Toronto (Schreurs et al. 2006). We have selected those analogue experiments that have the same set-up as our numerical experiments (i.e., no conveyor belt type experiments) and for which cross-sectional information was recorded. The properties of the granular materials used in the five analogue experiments are variable (e.g., sand: $\phi_{\text {peak }}$ between $33.2^{\circ}$ and $45^{\circ}, \phi_{\text {stable }} 29.2^{\circ}-39^{\circ}$; microbeads: $\phi_{\text {peak }}$ $22.3^{\circ}-26.4^{\circ}, \quad \phi_{\text {stable }} 20.6^{\circ}-26.2^{\circ}$; the exact values can be found in Schreurs et al. (2006)) and this probably affected the analogue results.
As the analogue granular materials are dilatant, they compact upon shortening. The strainhardening effect this causes has not been included in most of the numerical experiments. Three analogue experiments were monitored through glass sidewalls (Parma, Pavia, Toronto) while two recorded internal deformation with X-ray CT tomography (Bern, IFP). In the accompanying paper (Schreurs et al. 2006) it is shown that edge effects may influence the deformational structures close to the lateral (observation) sidewalls. The extent of edge effects may be evaluated by surface monitoring and cutting of sections after the final stage of the experiment. The quantification of parameters in all analogue and numerical experiments was as much as possible done in the same manner. Ranges of parameters that were measured in the analogue 
(g)

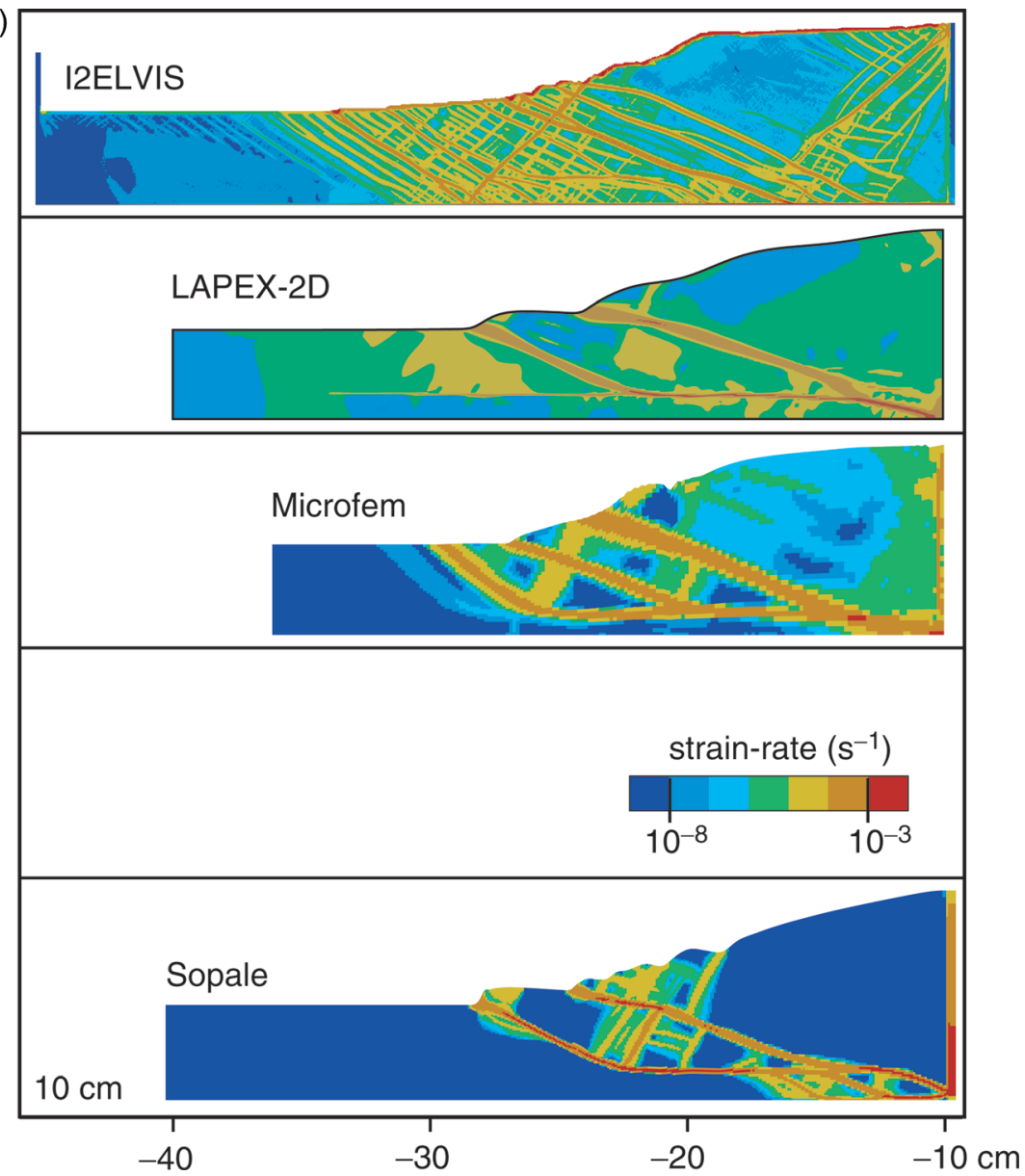

Fig. 2. Continued.

experiments (number of thrusts, dip angle, thrust spacing, fault-controlled shortening, microbeads layer activation and surface slope) are indicated in the figures and table which report the numerical values (Figs 3 and 4 and Table 3 ).

The comparison of our numerical results to the analogue models leads to the following observations: (1) The variability between numerical codes is about the same as the degree of variability between different analogue models. (2) The numerical codes produce the same overall structure and sense of forward-propagation seen in the analogue models. (3) Most of the analogue models show the forward thrust (at $2 \mathrm{~cm}$ displacement, Fig. 6a) propagating from a basal point located to the left of the lower right-hand corner, whereas most of the numerical models show the forward thrust propagating from this corner. This may reflect a difficulty in the numerical models of representing the velocity discontinuity at the corner. Panien et al. (2006) show that thrust localization near the mobile wall is sensitive to the exact implementation and smoothing of the applied velocity near the basal corner. Alternatively, the actual velocity discontinuity in the analogue models may not be so sharply defined as implied by the set-up (Fig. 1) and just a small exit slot may smooth the impact of the velocity discontinuity.

(4) Most of the analogue models show a distinct backthrust at $2 \mathrm{~cm}$ displacement which is poorly represented in most of the numerical models (except in the results of I2ELVIS, in which the mobile wall is part of the computational domain and has a $0.05 \mathrm{~cm}$ high exit slot at the base) (Fig. 6a). The absence of the backthrust in the numerical models may link to the strong preference for the first forward thrust 
(h)

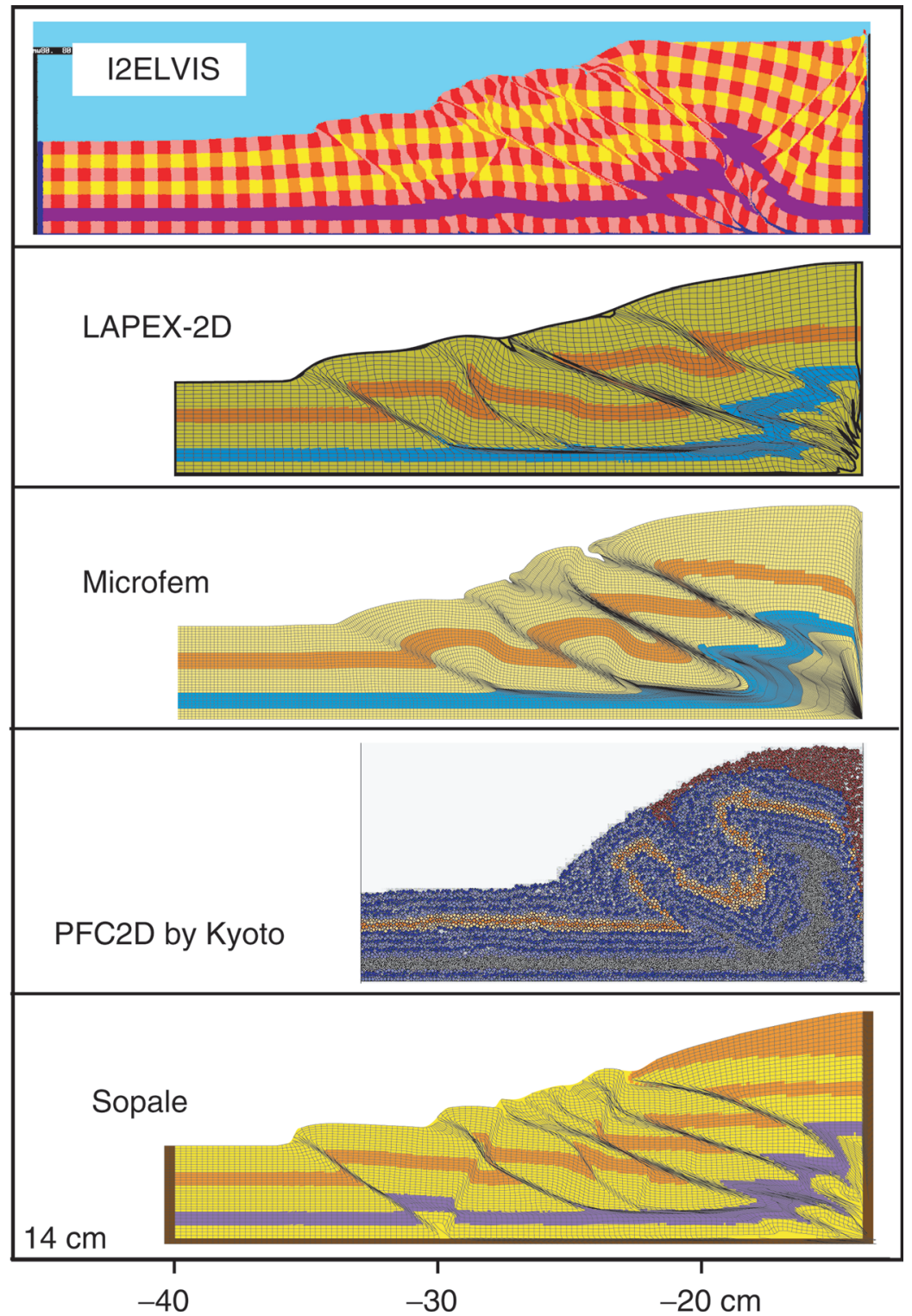

Fig. 2. Continued.

to initiate at the basal right-hand corner, as this configuration does not allow for a backthrust propagating up from the base. Interestingly, in the thrust wedge models of Ellis et al. (2004) (which were run with Microfem) a backthrust is visible and the first forward thrust roots to the left of the mobile wall. The exit slot below the mobile wall in these simulations may smooth the corner discontinuity, which suppresses the tendency for the thrust to localize in the basal corner and then allows a backthrust to form. Alternatively, the backthrust in these experiments could be due to the high angle of friction for the backstop. (5) The analogue models show the first thrust intersecting the surface to the left of the imposed wedge, as do the numerical models (Fig. 6a).

(6) Localization of deformation in shear zones in the initial stages of shortening occurs slightly earlier in the numerical models than in the 
(i)

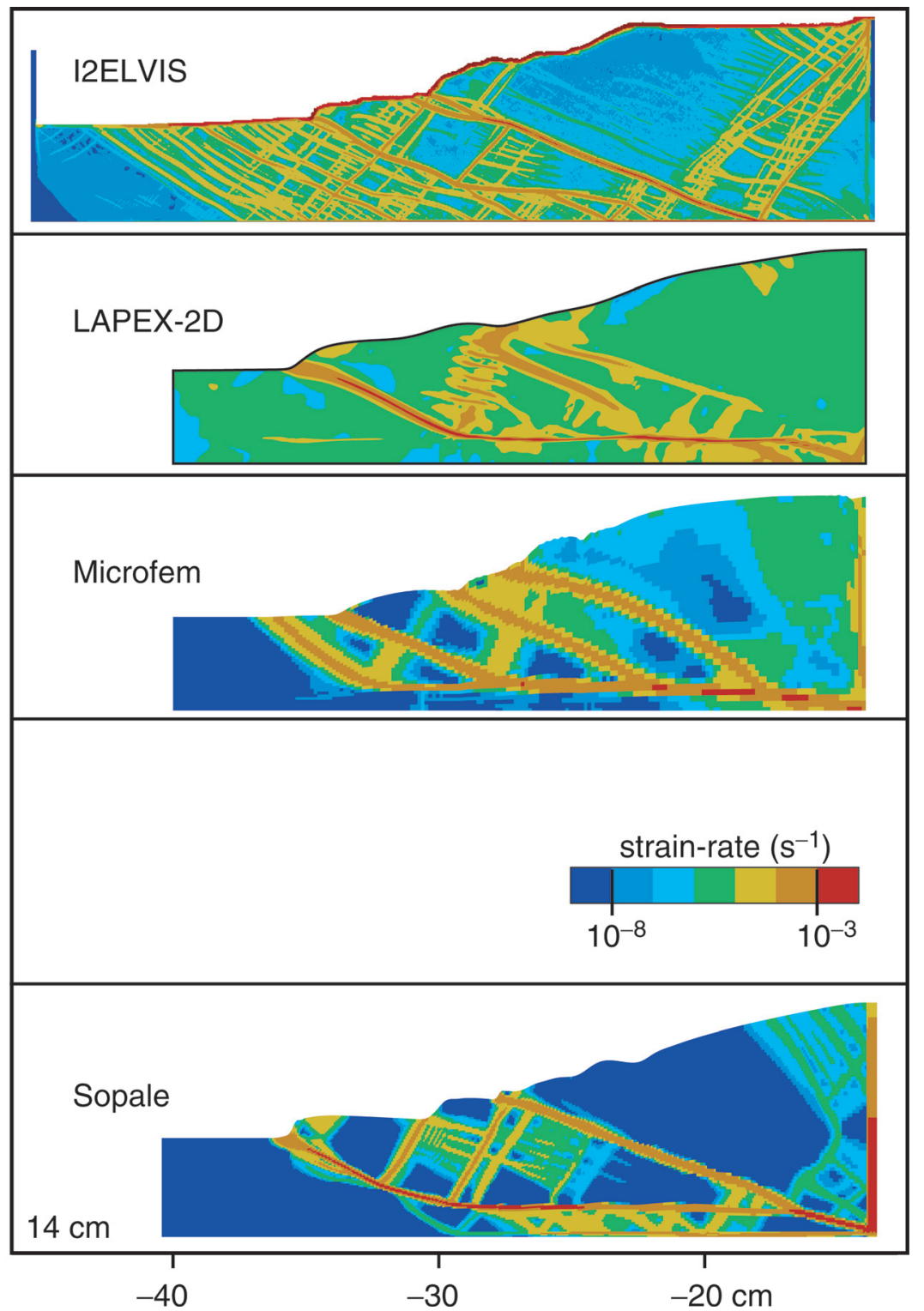

Fig. 2. Continued.

analogue models. The analogue models accommodate up to $0.5 \mathrm{~cm}$ of shortening through lateral compaction before visible faults form. (7) The variation in the number of thrusts between different numerical codes is approximately the same as the variation between equivalent analogue models (Fig. 3a). (8) The spacing of thrusts is less variable between the numerical codes than between the analogue experiments (Fig. 3c). (9) The dip angles of the forward thrusts are generally slightly lower in the analogue experiments (between $19^{\circ}$ and $33^{\circ}$ ) than in the numerical experiments (between $20^{\circ}$ and $39^{\circ}$ ) (Fig. 3b). The analogue experiments follow the theoretical values for Coulomb dip angles (Vermeer 1990) quite closely, which for the frictional properties of these five analogue experiments range between approximately $23^{\circ}$ and $29^{\circ}$. The predicted values for the numeric dip angles lie between $27^{\circ}$ (Coulomb dip angle) 
Table 3. Quantification of shortening experiments*

\begin{tabular}{|c|c|c|c|}
\hline \multirow[t]{2}{*}{ Code } & \multirow{2}{*}{$\begin{array}{c}\text { Fault } \\
\text { short. }^{\dagger} \text { at } \\
4 \mathrm{~cm}\end{array}$} & \multicolumn{2}{|c|}{$\begin{array}{l}\text { 'Microbeads' } \\
\text { layer }\end{array}$} \\
\hline & & Activated at & $\begin{array}{l}\text { Detachm. } \\
\text { length }\end{array}$ \\
\hline $\begin{array}{l}\text { Abaqus/ } \\
\text { Standard }\end{array}$ & n.a. & n.a. & \\
\hline I2ELVIS & $2.5-2.6$ & never & \\
\hline LAPEX-2D & $1.9-2.8$ & 3 & 7.4 \\
\hline Microfem & $1.5-2.3$ & 4 & 6.2 \\
\hline NISA/Static & n.a. & n.a. & \\
\hline $\mathrm{PFC}^{2 \mathrm{D}} /$ Kyoto & $1.5-1.8$ & 6 & 8.0 \\
\hline Sopale & $2.0-2.8$ & 4 & 5.0 \\
\hline $\begin{array}{c}\text { Analogue } \\
\text { ranges }\end{array}$ & $1.9-2.9$ & $5.0-$ never & $2.2-9.3$ \\
\hline
\end{tabular}

*All values referred to sandbox scale in $\mathrm{cm}$. Output stages typically available at $0,0.5,1,2$ and then every $2 \mathrm{~cm}$ of shortening.

${ }^{\dagger}$ Fault-controlled horizontal shortening determined by cut-off points between layers and the faults.

Analogue values from experiments of University of Bern, University of Parma, University of Pavia, IFP Rueil-Malmaison and University of Toronto (Schreurs et al. 2006).

and $45^{\circ}$ (non-dilatant Roscoe dip angle). The first thrusts may be influenced by the surface wedge, leading to lower values for their dip angles. (10) The surface slopes measured for the numerical models plot around the lower ranges of the analogue surface slopes (Fig. 4). This is probably caused by the generally lower strength of the numerical materials in comparison with many of the analogue materials (Table 1).

Most of the differences between the numerical and analogue models may be attributed to the difficulty in representing the exact set-up of the analogue model and to differences in material properties. Despite these differences, the numerical models still produce a similar taper geometry and evolutionary style to the analogue models.

\section{Extension experiment}

\section{Model set-up}

The extension experiment examines the influence of a weak, basal viscous layer on normal fault localization and propagation in overlying brittle materials. The model is $20 \mathrm{~cm}$ wide and $3.5 \mathrm{~cm}$ high (Fig. 1b). It consists of three 'sand' layers (only coloured differently) and a $10 \mathrm{~cm}$ wide and $0.5 \mathrm{~cm}$ high layer of viscous PDMS, which overlies the central basal part of the model. A thin rigid sheet covering the base of the model extends from the middle to the right lateral wall and is attached to it. Extension is achieved by moving the right wall outward to

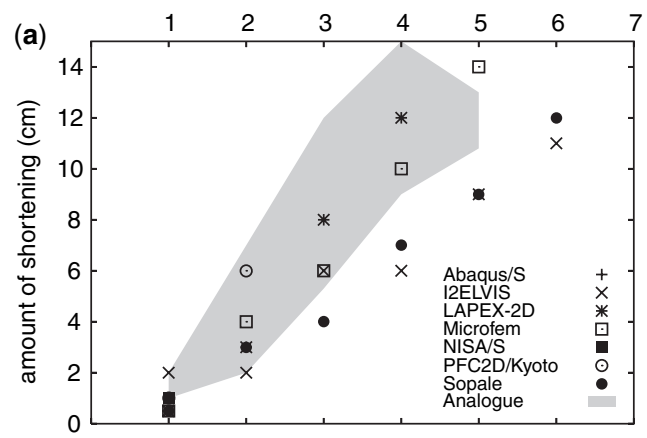

(b)
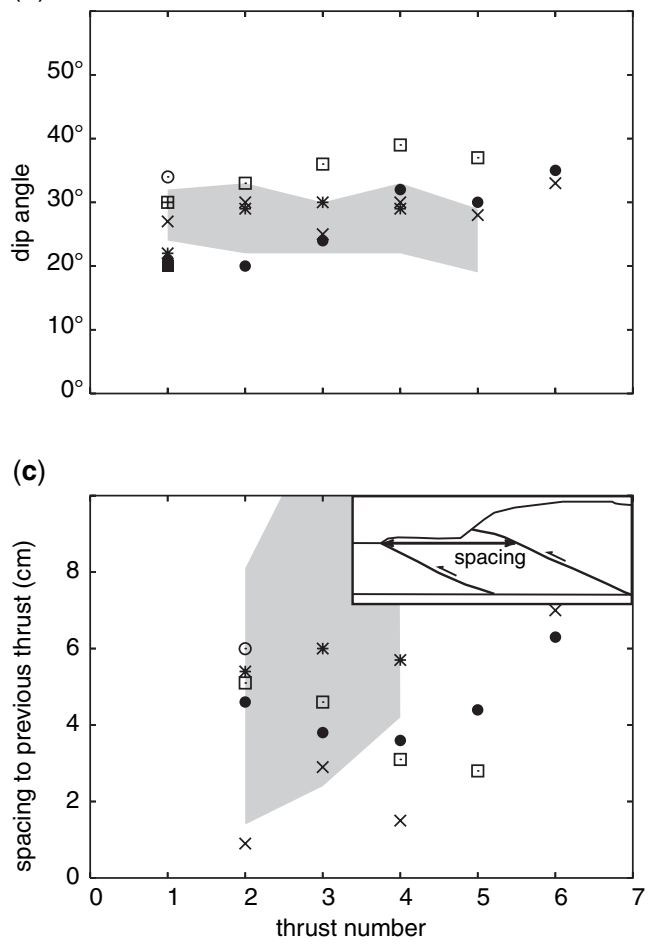

Fig. 3. (a) The amount of displacement at which a forward thrust forms shows that all experiments have forward propagation of thrust formation. (b) Dip angle of forward thrusts at the moment of their initiation. A dip angle of approximately $19^{\circ}$ is expected for the first thrust if its location was entirely controlled by the initial wedge. (c) Spacing to the previous forward thrust measured at the moment of initiation of the new forward thrust. Inset shows how thrust spacing is measured. The quantities in (b) and (c) have been measured at the same stages of shortening as depicted in (a). The grey bands denote the range of values measured for the analogue experiments of University of Bern, IFP Rueil-Malmaison, University of Parma, University of Pavia and University of Toronto (see also Fig. 6 and Schreurs et al. 2006). 

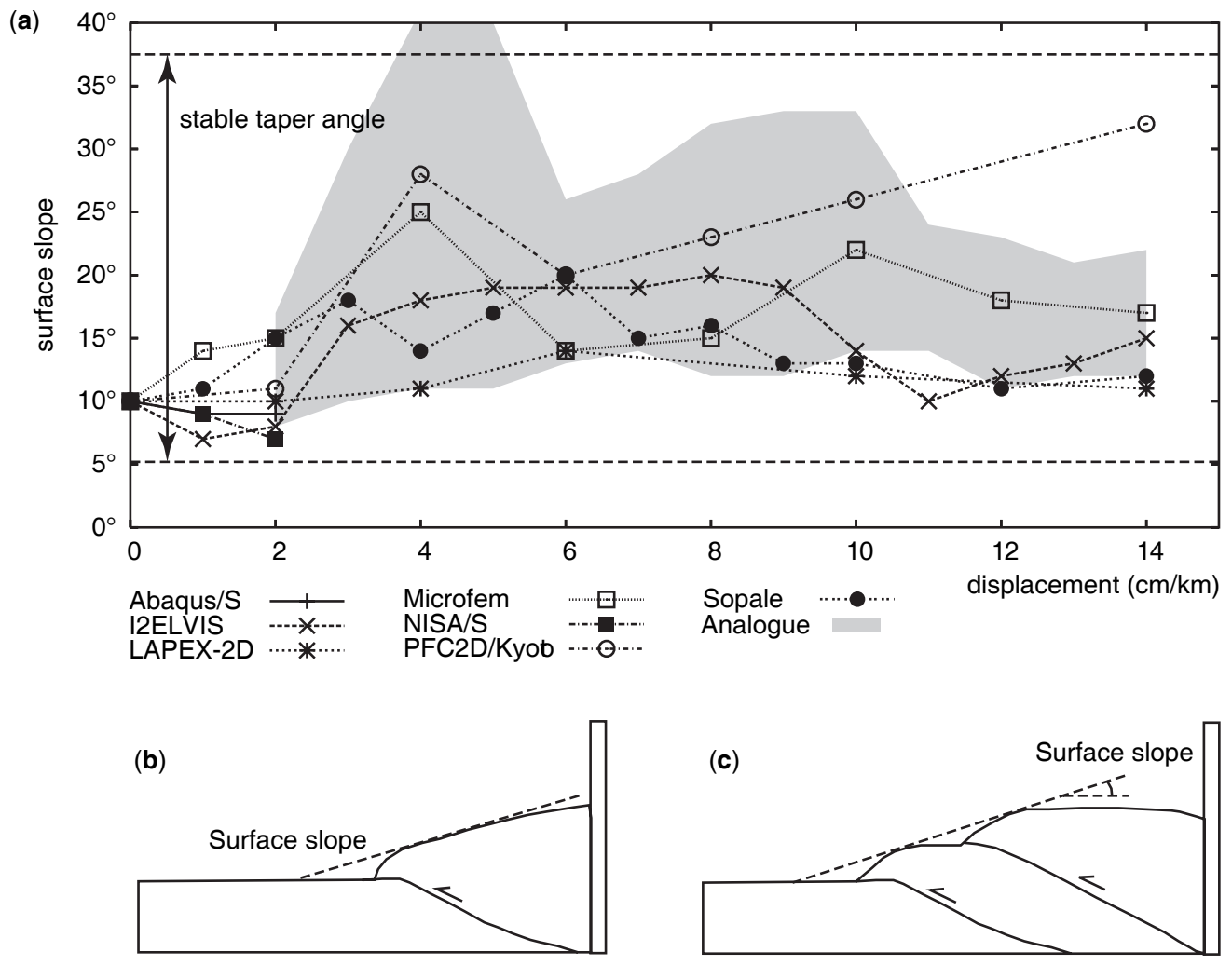

Fig. 4. (a) Surface slope versus amount of displacement. Surface slopes as measured in the analogue experiments of University of Bern, IFP Rueil-Malmaison, University of Parma, University of Pavia and University of Toronto (Schreurs et al. 2006) are shown as a grey band. (b) Schematic figure showing how surface slope has been determined for the early stages of shortening. It is clear that the initial surface slope angles are difficult to determine. (c) For two or more thrusts, the surface slope has been determined by drawing the enveloping surface.

the right at a rate of $2.5 \mathrm{~cm} / \mathrm{hr}$. This velocity is also transmitted to the right basal half of the model through the basal sheet. The tip of the basal sheet forms a migrating velocity discontinuity. The base of the model, the basal sheet and the sidewalls are again covered with Alkor foil (prescribed boundary friction is $19^{\circ}$ ). The boundary condition of silicone overlying this foil was treated differently in the models. The extension experiment was run with six numerical codes (Abaqus/Standard, I2ELVIS, LAPEX-2D, Microfem, SloMo and Sopale; Table 4), which were all non-dilatational for this experiment. The initial geometries are shown in Figure 7a. The following code-specific assumptions apply:

Abaqus/Standard. Basal friction is applied along the entire bottom boundary. The change in velocity at the basal velocity discontinuity is accommodated over 4 elements $(0.4 \mathrm{~km}$ scaling to $0.4 \mathrm{~cm})$. The model diverged after $1.5 \mathrm{~cm}$ of displacement.
I2ELVIS. Basal friction is applied along the whole bottom boundary. The rigid mobile wall and a $0.5 \mathrm{~mm}$ thin rigid plate (with a background viscosity of $10^{14} \mathrm{Pas}$ and a shear modulus of $10^{2}-10^{4} \mathrm{MPa}$ ) are included into the computational domain. During extension, part of the weak 'air' layer at the top of the model is spontaneously displaced from behind the mobile wall.

LAPEX-2D. Basal points above the moving sheet are assigned the velocity of the sheet, whereas basal points to the left of the moving sheet are held fixed. The change in velocity at the basal velocity discontinuity is accommodated over 4 elements $(2.7 \mathrm{~km}$ scaling to $0.27 \mathrm{~cm})$.

Microfem. Basal friction is applied along the entire bottom boundary. The change in velocity at the basal velocity discontinuity is smoothed over 3 nodes $(0.25 \mathrm{~km}$ scaling to $0.25 \mathrm{~cm})$. The domain width is $25 \mathrm{~km}(25 \mathrm{~cm})$. 

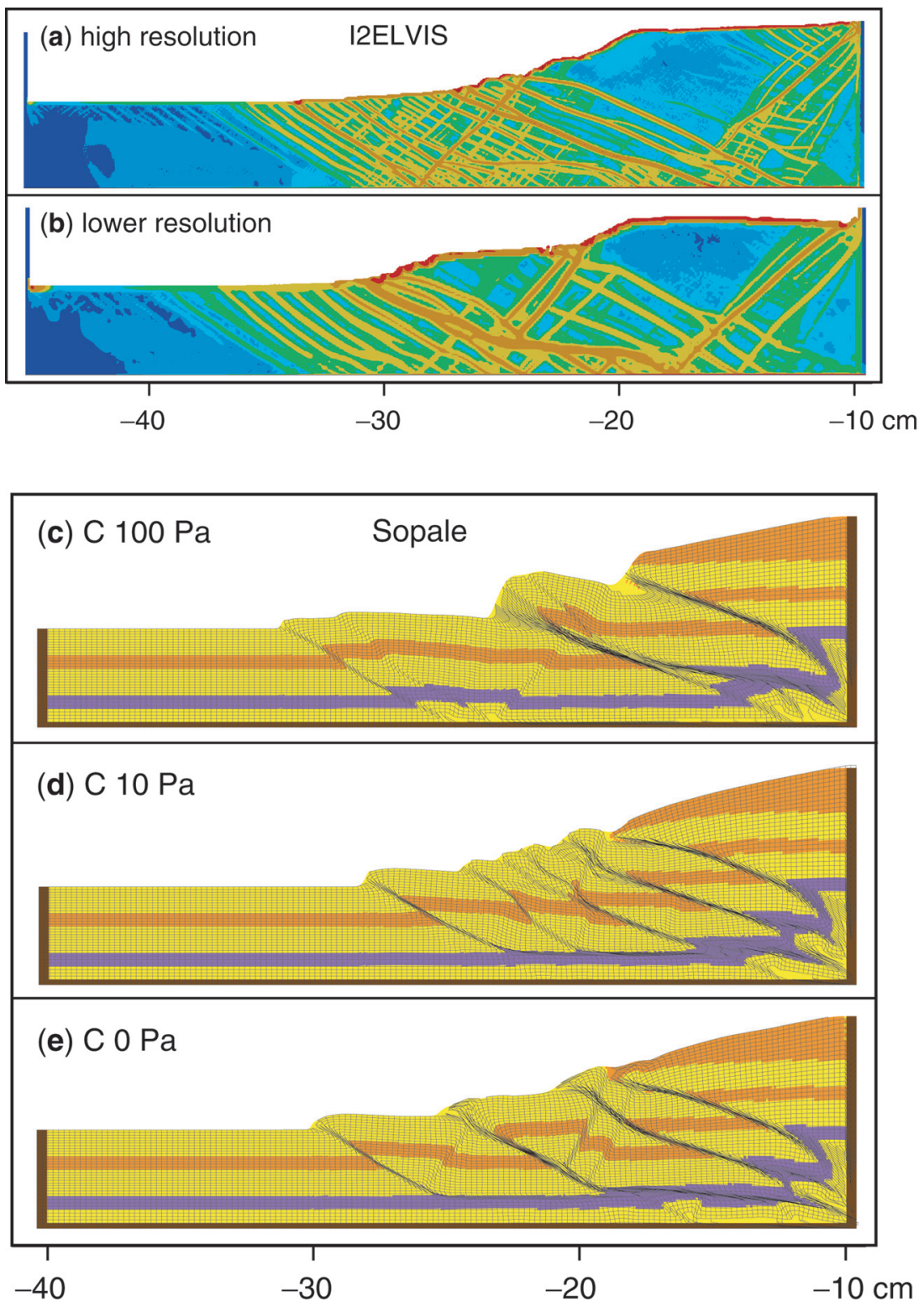

Fig. 5. Sensitivity tests for the shortening experiment. I2ELVIS results after $10 \mathrm{~cm}$ of displacement for (a) high resolution (normalized element size 0.05 as in Fig. 2) and (b) lower resolution (normalized element size 0.1). Sopale results after $10 \mathrm{~cm}$ of displacement for (c) a cohesion of $100 \mathrm{~Pa}$ (sandbox scale), (d) a cohesion of $10 \mathrm{~Pa}$ (as in Fig. 2), and (e) a cohesion of $0 \mathrm{~Pa}$.

SloMo. Basal points above the moving sheet are assigned the velocity of the sheet, whereas points to the left are held fixed. The basal velocity discontinuity is accommodated by a linear decrease in velocity over $0.5 \mathrm{~cm}$ (10 elements).

Sopale. Basal points above the moving sheet are assigned the velocity of the sheet, whereas basal points to the left of the moving sheet are held fixed. The change in velocity at the basal velocity discontinuity is accommodated over 4 elements $(0.2 \mathrm{~km}$ scaling to $0.2 \mathrm{~cm})$. The vertical sides are held fixed (however, this boundary condition has no effect as deformation does not propagate to the lateral ends of the model). 
(a)

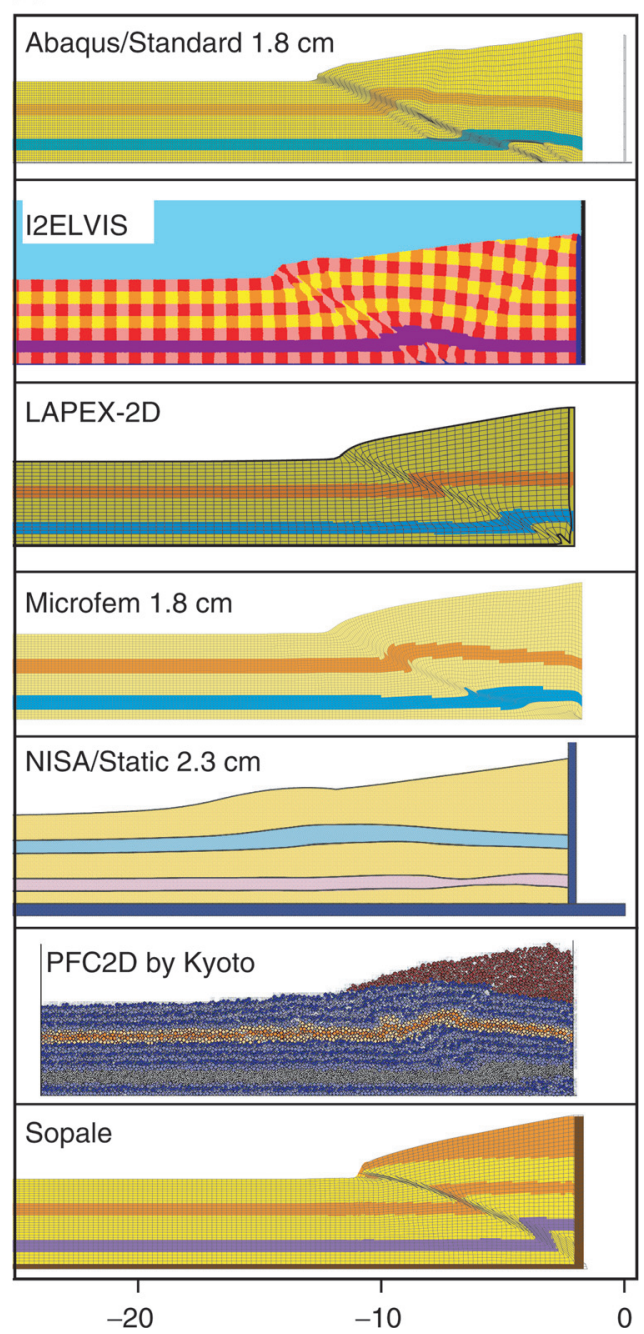

Numerical

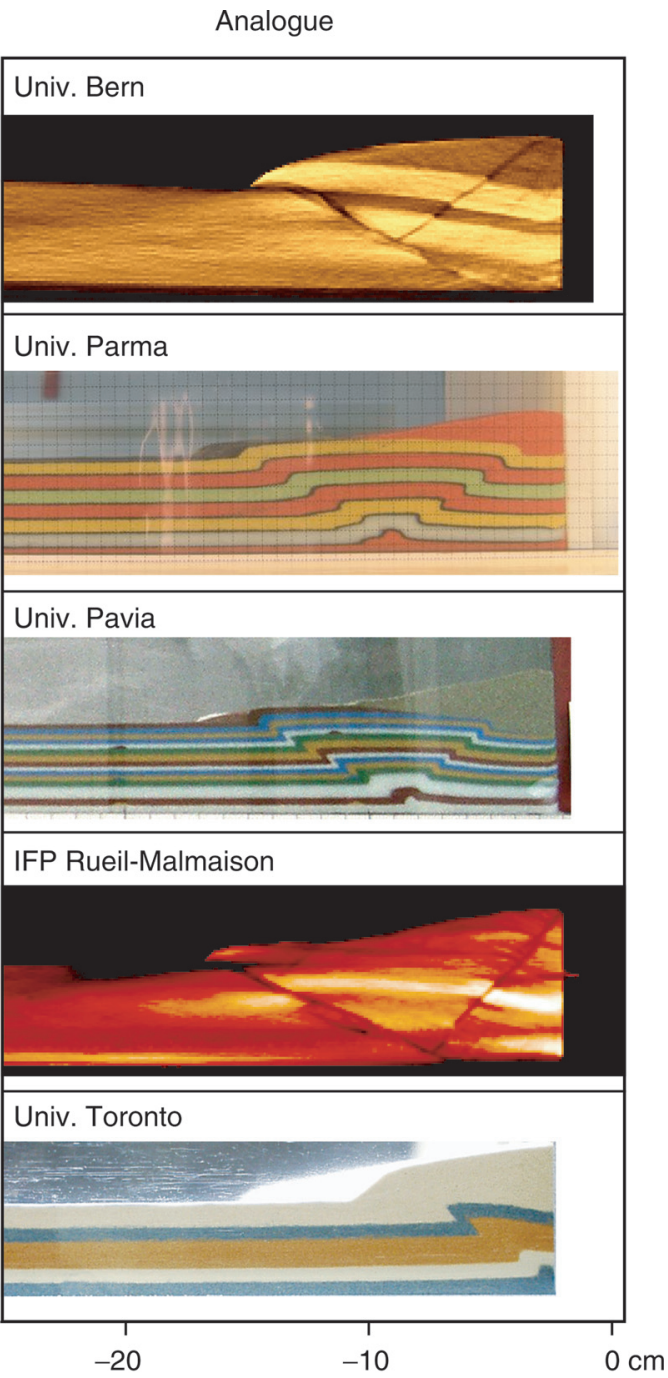

Fig. 6. Comparison of numerical and analogue results for the shortening experiment. (a) $2 \mathrm{~cm}$ of shortening (note that the model domain has been cropped on the left-hand side). (b) $14 \mathrm{~cm}$ of shortening.

\section{Model results}

The evolution of the six numerical models is shown in Figure 7 with plots of geometry and strain-rate (after 1,2 and $5 \mathrm{~cm}$ of extension) and pressure (after 1 and $5 \mathrm{~cm}$ ). Measurements of fault dip, location of fault initiation, faultcontrolled extension and fault migration are shown in Table 5 and Figure 8. The measurement procedure was the same as for the shortening experiment. The initial set-up of the experiment is symmetric and the very first deformation structures should, therefore, be symmetric. The symmetry is disrupted as the basal sheet is pulled out from underneath the model.

Analysis of the numerical results allows the following observations (Figs 7 and 8, Table 5): (1) Extension first leads to the formation of two conjugate shear zones centred at the basal velocity discontinuity (the tip of the basal sheet) with a dip angle of $45^{\circ}$ to $55^{\circ}$ (Fig. $7 \mathrm{~b}$, Table 5). The dip angles are within the values expected for dynamic pressure-dependent non-dilatant Mohr-Coulomb shear zones, where predictions 
(b)
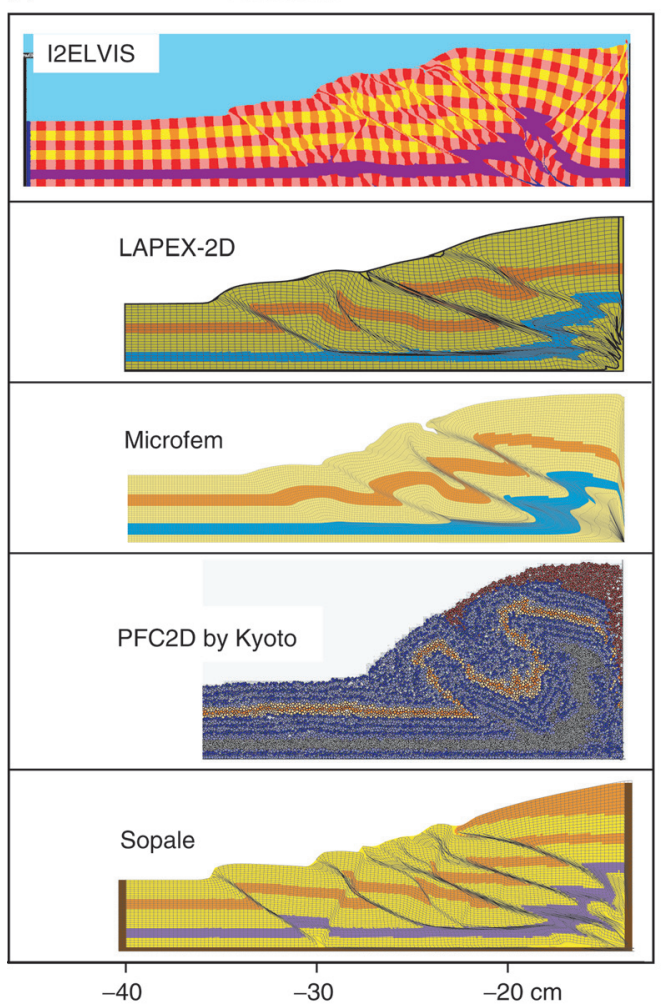

Analogue
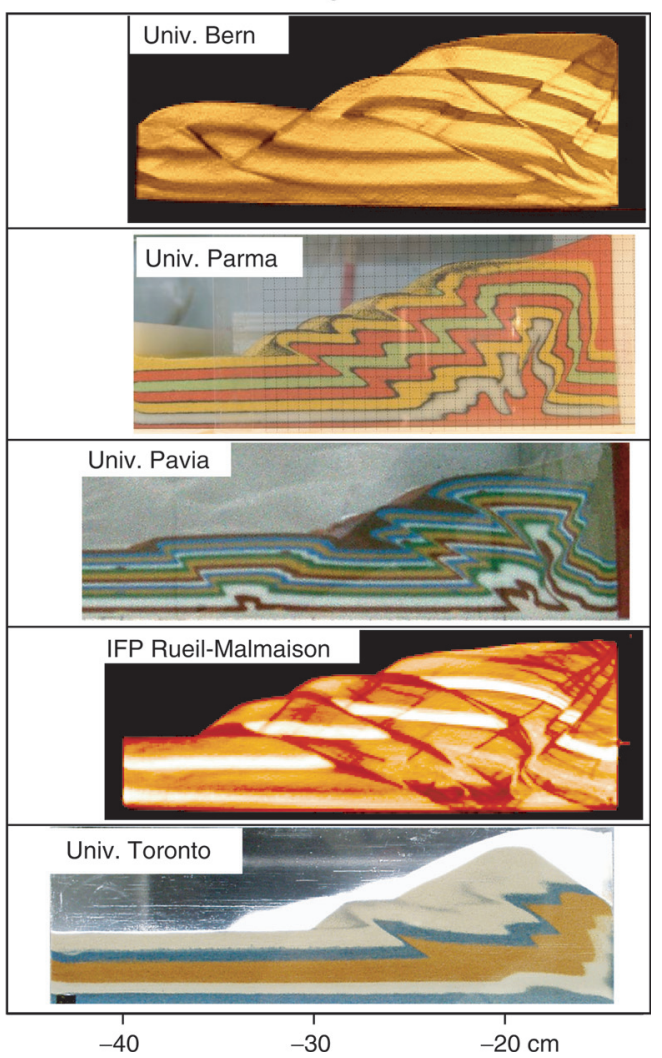

Fig. 6. Continued.

WebColor

Table 4. Extension experiments

\begin{tabular}{|c|c|c|c|c|c|c|c|c|c|}
\hline Code & Method* & Nodes $^{\dagger}$ & $\begin{array}{l}\text { Track } \\
\text { points }\end{array}$ & $\begin{array}{l}\text { Norm. } \\
\text { elem. } \\
\text { size }\end{array}$ & $\begin{array}{c}\mathrm{E}^{\S} \\
(\mathrm{MPa})\end{array}$ & $v^{\|}$ & $\begin{array}{c}\eta^{\top} \\
(\mathrm{Pa} \mathrm{s})\end{array}$ & $\Delta t^{1}$ & Veloc. $^{2}$ \\
\hline $\begin{array}{l}\text { Abaqus/ } \\
\text { Standard }\end{array}$ & FEM & $201 \times 36$ & n.a. & 0.1 & 0.5 & 0.25 & $5 \mathrm{e} 6$ & varies & $2.2 \mathrm{~cm} / \mathrm{yr}$ \\
\hline I2ELVIS & $\mathrm{FDM}+$ & 5 & 0 & & 3 & 0.5 & $1 \mathrm{e} 1$ & $/ 0.008 \mathrm{~h}$ & $2.5 \mathrm{~cm} / \mathrm{hr}$ \\
\hline$-2 D$ & $\mathrm{FDM}+\mathrm{MIC}$ & $301>$ & 340000 & 0.0577 & 0.1 & 0.125 & $4.5 \mathrm{e} 10$ & $1 \mathrm{yr} /$ & $1 \mathrm{~cm} / \mathrm{yr}$ \\
\hline licrofem & ALE & $201 \times$ & 12261 & 0.1 & n.a & $\mathrm{n}$. & $4 \mathrm{e} 13^{3}$ & $700 \mathrm{yr} / 22.2 \mathrm{~s}$ & $2.2 \mathrm{~cm} / \mathrm{yr}$ \\
\hline $\mathrm{oM}$ & FEM & $401 \times$ & 94500 & 0.05 & 0.005 & 0.50 & $1 \mathrm{e} 9$ & $/ 5 \mathrm{~s}$ & $2.5 \mathrm{~cm} / \mathrm{hr}$ \\
\hline Sopale & ALE & $401 \times 71$ & 253411 & 0.05 & n.a. & n.a. & $4.6 \mathrm{e} 13$ & $1000 \mathrm{yr} / 7.2 \mathrm{~s}$ & $0.5 \mathrm{~cm} / \mathrm{yr}$ \\
\hline
\end{tabular}

${ }^{*}$ FEM $=$ Finite Element Method, FDM $=$ Finite Difference Method, ALE = Arbitrary Lagrangian Eulerian, MIC = Marker-in-Cell.

${ }^{\dagger}$ Nodes in horizontal $\times$ vertical direction.

Normalized element size is measured as the square root of element area, scaled to sandbox scale $(\mathrm{cm})$.

${ }^{\S}$ Young's modulus, scaled to sandbox scale.

"Poisson ratio.

"Background viscosity (for sand), scaled to sandbox scale. The numerical value for the viscosity of the silicone for the scaled experiments can be derived from the analogue viscosity value (5e4 Pa s), the numerical velocity and the scaling relationships (Equation 3 ).

${ }^{1}$ Time step used in the calculations. First value is for the numerical model, second value is its equivalent, scaled to the sandbox scale.

${ }^{2}$ Velocity on sandbox scale is $2.5 \mathrm{~cm} / \mathrm{hr}$ for all experiments.

${ }^{3}$ Equivalent linear viscosity; a non-linear viscosity was used in the calculations. 
(a)
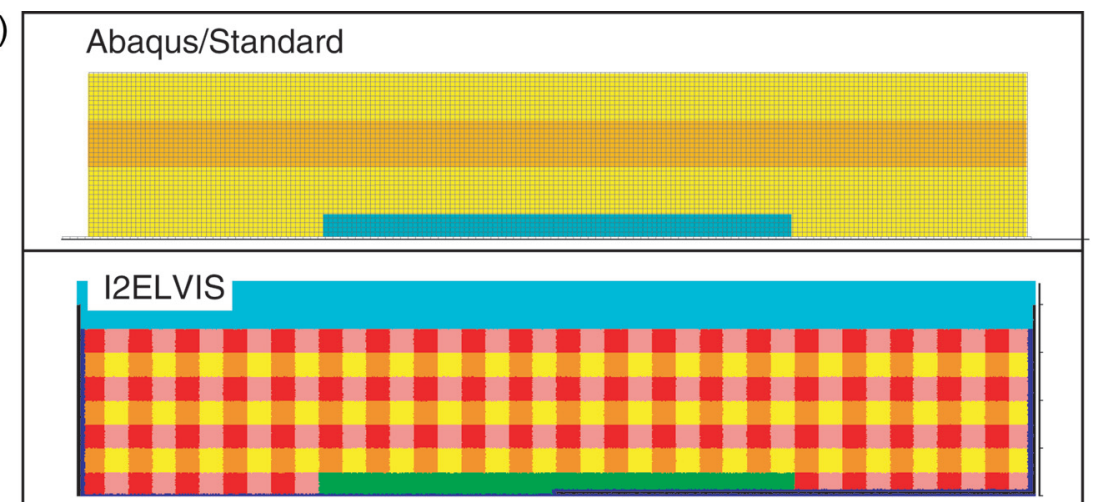

LAPEX-2D

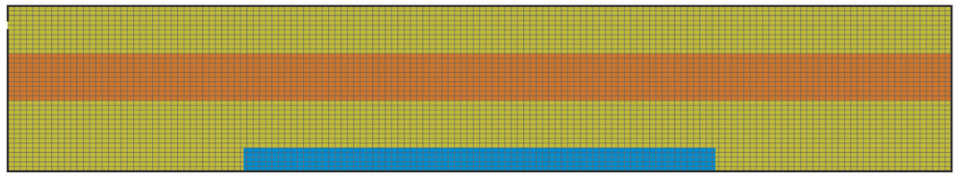

Microfem

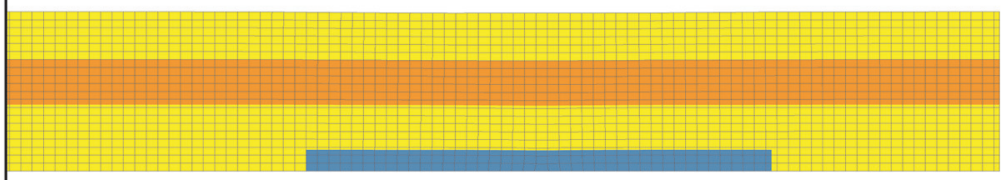

SloMo

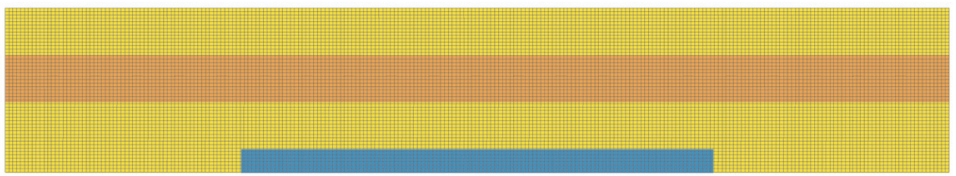

\section{Sopale}

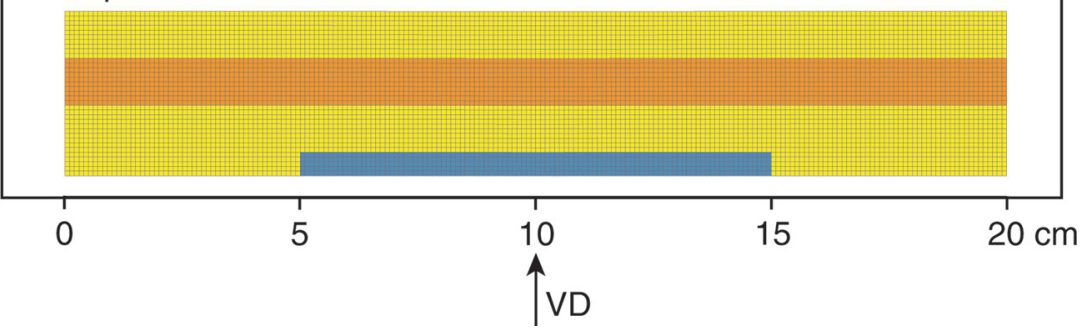

Fig. 7. Results for the extension experiment. All quantities (including strain-rates and pressures) are scaled down to the sandbox scale. (a) Initial geometries. The grid of Abaqus/Standard is the calculation grid, while for LAPEX-2D, Microfem, SloMo and Sopale the shown grid is (a subset of) the Lagrangian tracking grid. (b) Geometries after $1 \mathrm{~cm}$, including analogue examples of University of Bern and IFP Rueil-Malmaison. VD = velocity discontinuity. (c) Strain-rates after $1 \mathrm{~cm}$. (d) Dynamic pressures after $1 \mathrm{~cm}$. (e) Geometries after $2 \mathrm{~cm}$. (f) Strain-rates after $2 \mathrm{~cm}$. (g) Geometries after $5 \mathrm{~cm}$, including analogue examples of University of Bern and IFP Rueil-Malmaison. (h) Strainrates after $5 \mathrm{~cm}$. (i) Dynamic pressures after $5 \mathrm{~cm}$. 
(b)

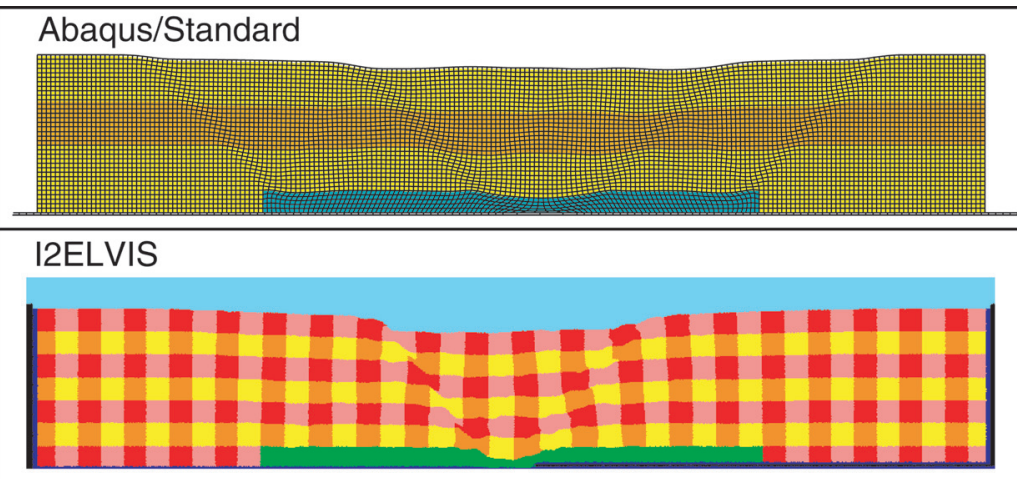

LAPEX-2D

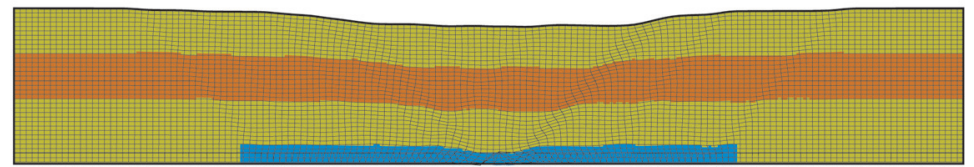

Microfem

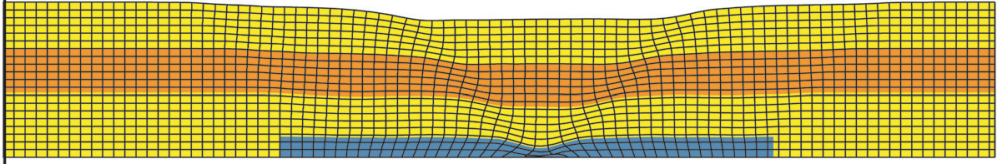

SloMo

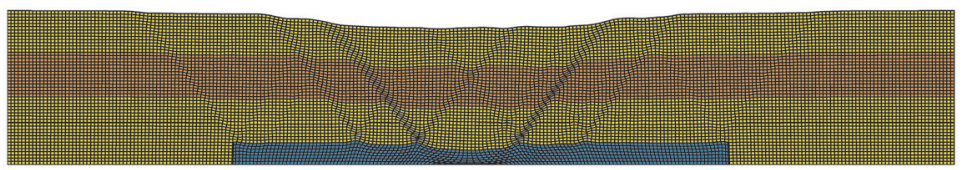

\section{Sopale}

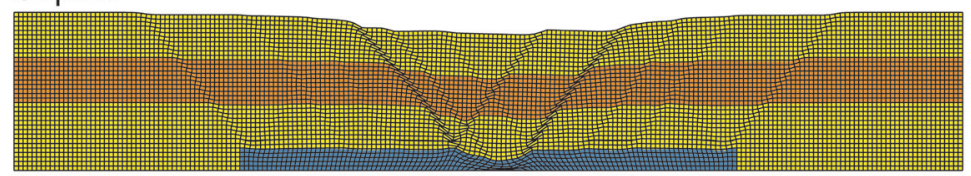

Analogue - Univ. Bern

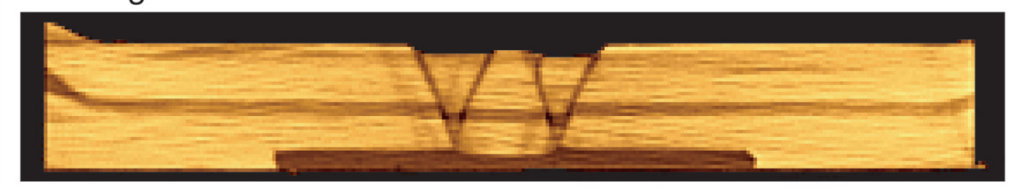

Analogue - IFP Rueil-Malmaison

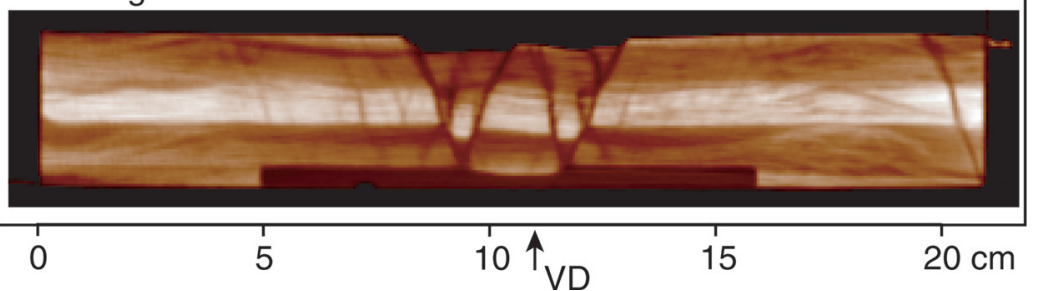

Fig. 7. Continued. 


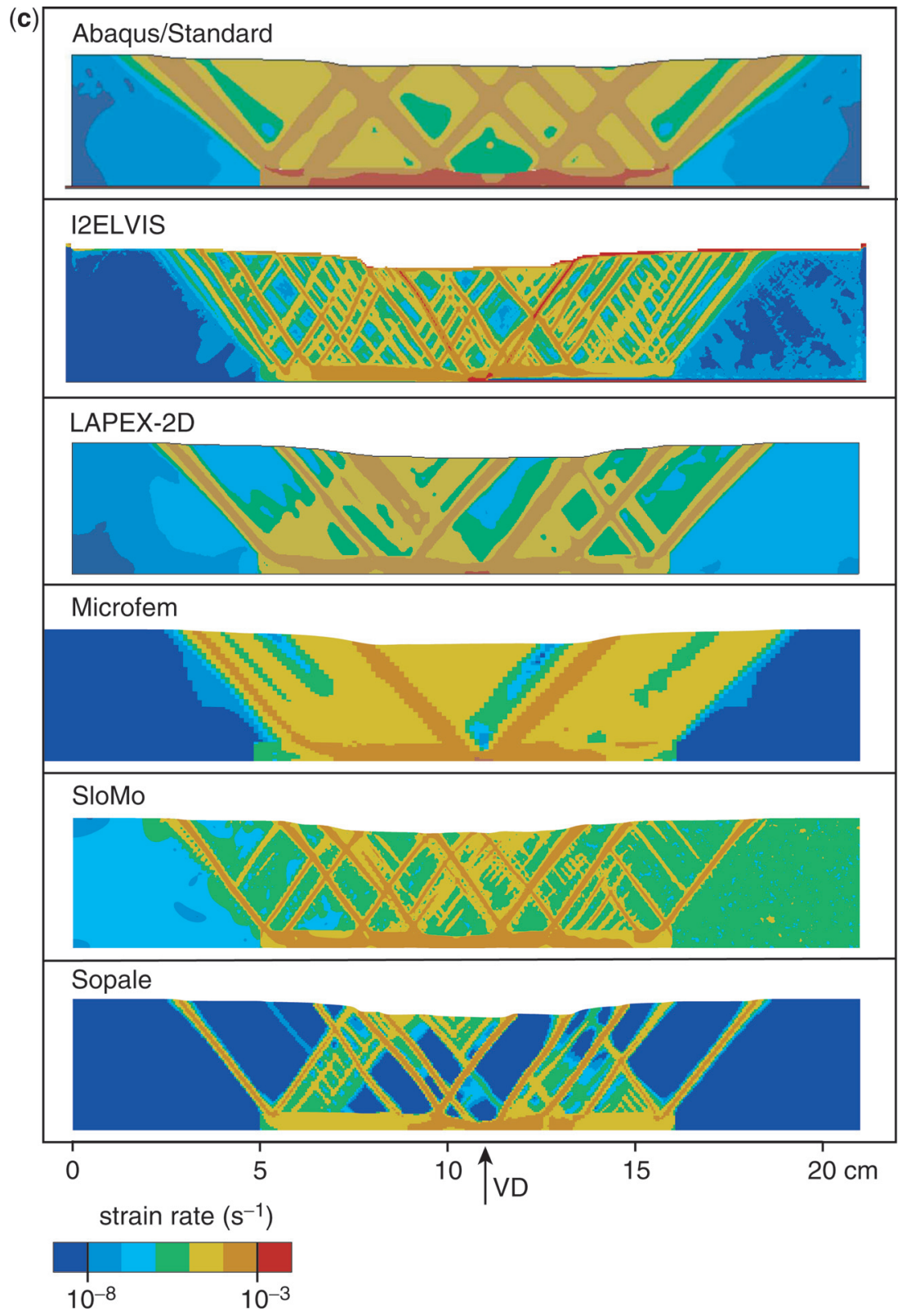

Fig. 7. Continued.

for fault inclination range between $45^{\circ}$ (Roscoe angle) and $45^{\circ}+\phi / 2$ (Coulomb angle) (Vermeer 1990). The agreement in fault dip angles among the models is reflected in the similarity in dynamic pressures at 1 (and also $5 \mathrm{~cm}$ ) of extension (Figs 7d and i). (2) The viscous layer distributes deformation quickly and at $1 \mathrm{~cm}$ of extension distributed shear zones are visible in all models (Fig. 7c). The left and right side edges of the viscous layer are found quickly (Table 5).

(3) With continued extension, the shear zones migrate to the right, the silicone layer thins and the surface depression becomes wider and asymmetric in shape (Figs 7d-g). The structural evolution of all the large-deformation models is very similar, especially in light of the differences in basal boundary condition. This suggests that 


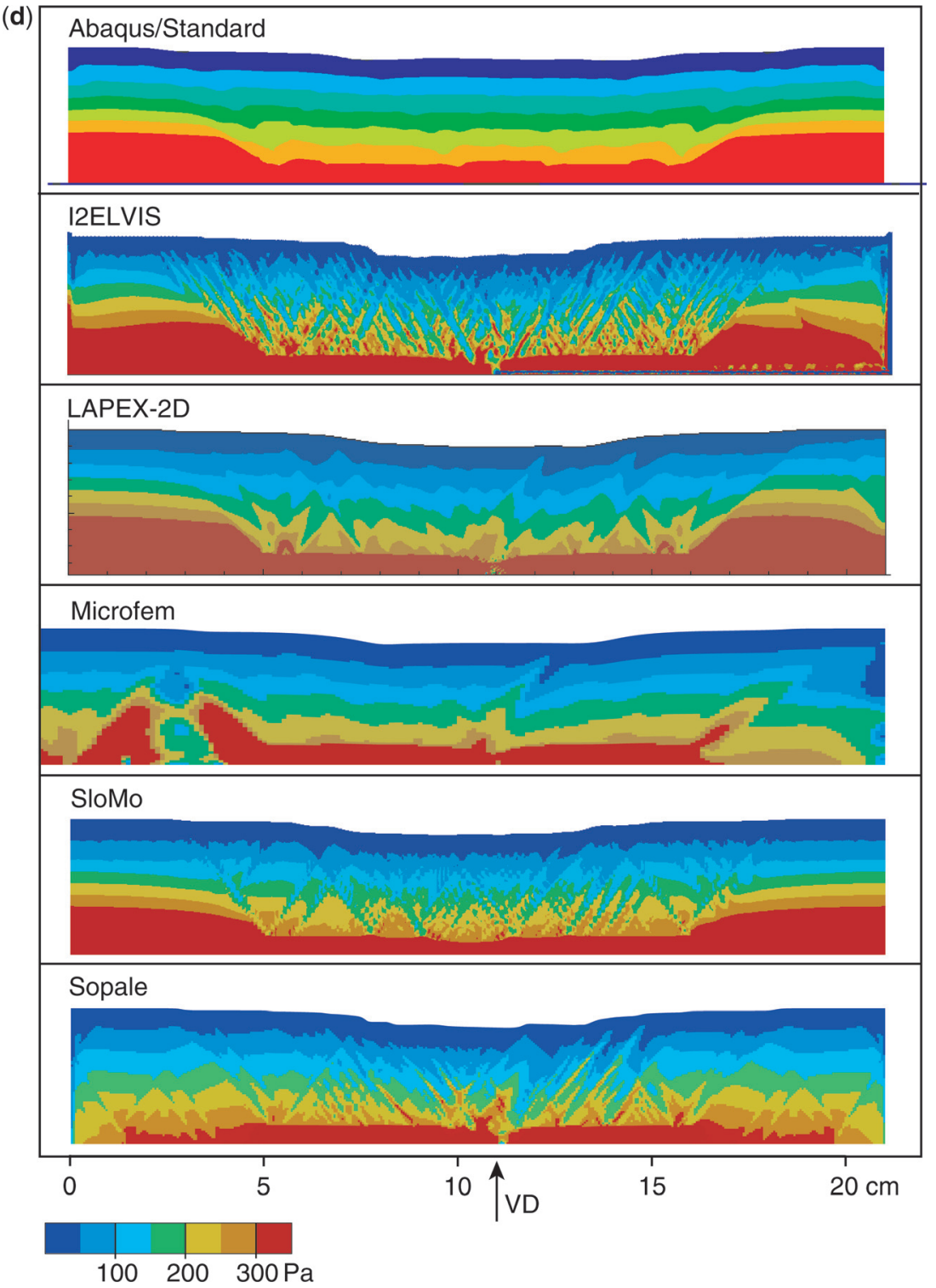

Fig. 7. Continued.

the basal contact is not as important as the interaction between the moving velocity discontinuity and the viscous layer. (4) The evolution in dip angle of the first formed shear zone to the right of the velocity discontinuity is fairly similar for the different models (Fig. 8a). For larger amounts of extension $(>5 \mathrm{~cm})$, we find that block rotation becomes more pronounced and fault dip decreases.

(5) The first formed shear zone moves to the right as the basal sheet is pulled out (Fig. 8b). A general trend is that fault migration is slower than the velocity with which the basal sheet is pulled because deformation is taken up by the block to the right of the first formed shear zone (e.g., through the formation of new shear zones). The differences between the numerical models are small and the effect on the resulting geometries is small as well. (6) The amount of fault-controlled extension is again highly variable (Table 5), as was observed for the shortening experiment.

(7) The dynamic pressure field (Figs 7d and i) is more heterogeneous than the strain-rate field 
(e)
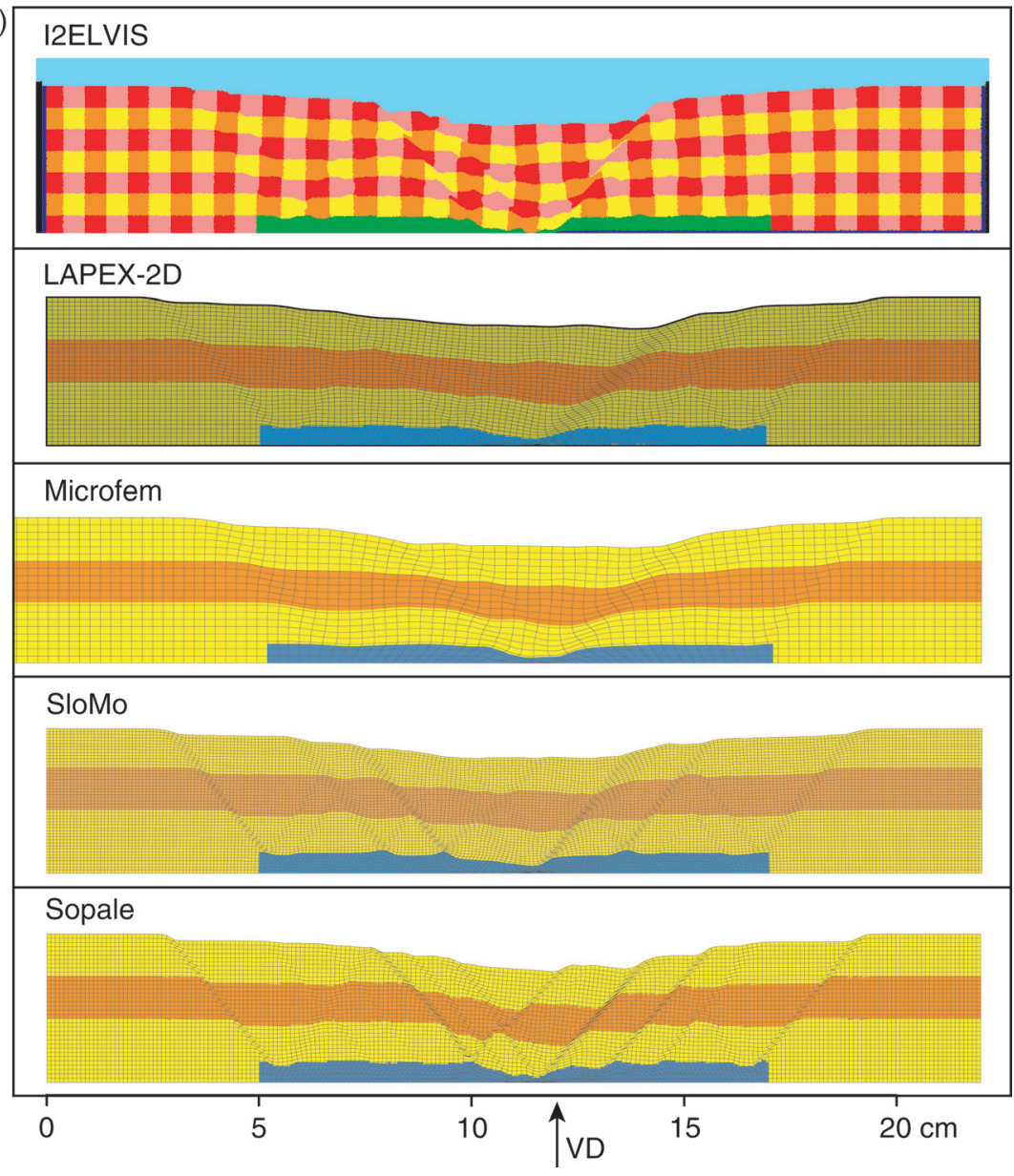

Fig. 7. Continued.

(Figs 7c and h) and visualizes both existing shear zones (currently or previously active) and potential shear zones (which are not necessarily activated). A comparison of the pressure fields for LAPEX-2D and Sopale shows that the seemingly rigid footwall blocks at the sides of the model behave in a different way in the two models. In Sopale the footwalls are at yield, whereas in LAPEX-2D they show an infinitesimal amount of elastic deformation ( $10^{-5}$ approximately) and are not at yield. In a purely viscous-plastic code (such as Sopale) any amount of deformation in a high-viscosity limit brings the stresses immediately on yield. This is not the case for a visco-elasto-plastic code where the material has an additional freedom to deform elastically. The dynamic pressure for Abaqus/Standard is less well resolved due to the relatively low resolution of the model, which may perhaps also incorporate a certain degree of pressure smoothing. The pressure plots for Microfem show the effects of the stick-slip friction basal boundary condition. This creates a region of enhanced dynamic pressure in the left footwall block, which is not seen in the results for the other codes. However, the enhanced pressures do not have a large influence on deformation since the average strain-rates in this region are low.

\section{Localization of shear deformation}

Comparison of the six experiments shows that the degree of focussing of deformation on shear zones may vary significantly (Table 5, Fig. 7). Results from I2ELVIS and Sopale demonstrate 


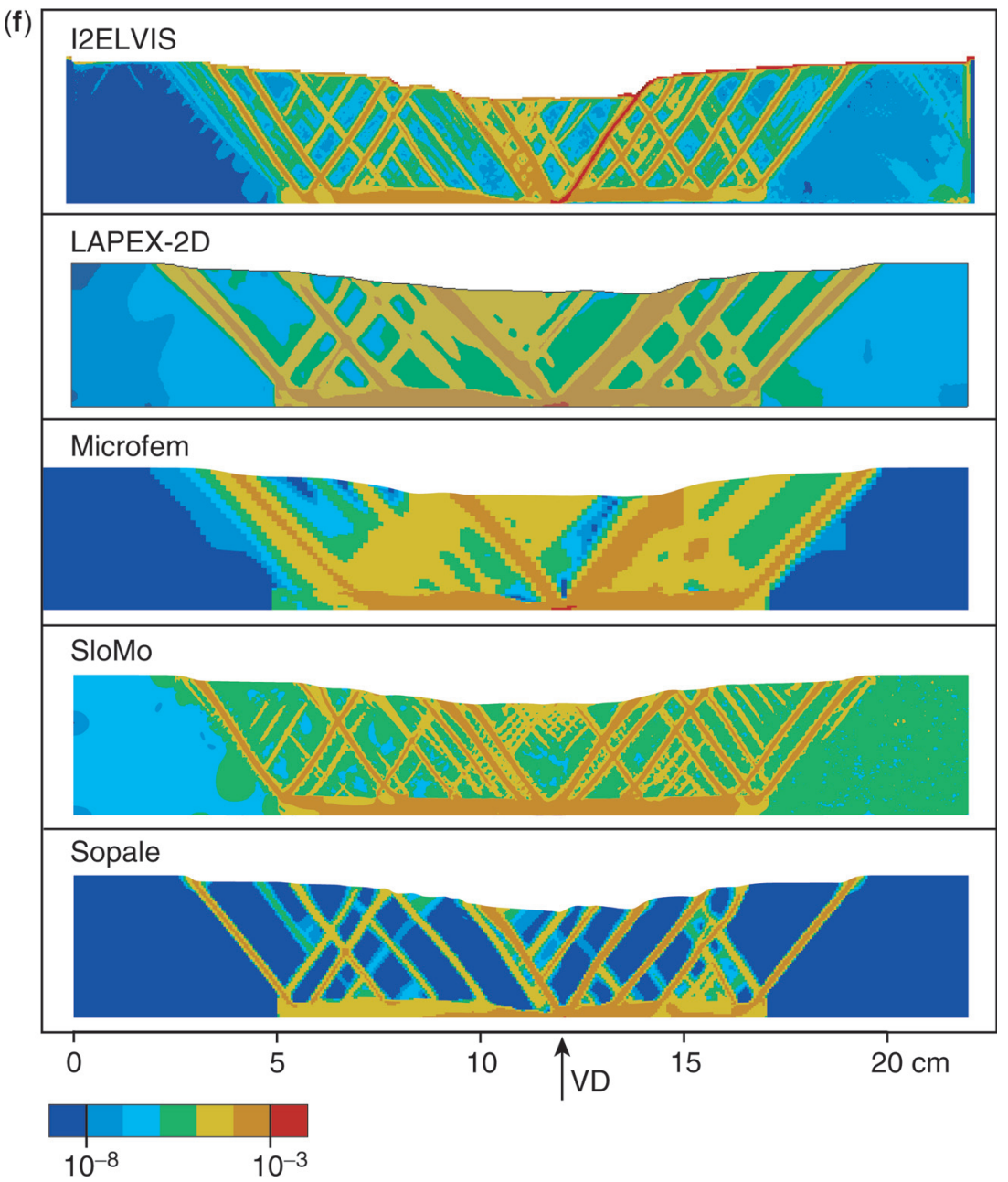

Fig. 7. Continued

that both the degree of localization and the number of shear zones that form strongly increases with increasing resolution of the numerical grid. This can also be seen from a comparison of the results from Microfem (lower resolution ALE code) and Sopale (higher resolution ALE code) (Fig. 7). According to Cundall (1990), the ratio of elastic bulk modulus to lithostatic pressure is an important parameter for fault spacing, whereby an increase in this ratio decreases fault spacing. In nature, the value of this dimensionless ratio is expected to vary over orders of magnitude (for example, between 17 and 4432, using an elastic modulus of $10^{10}-10^{11} \mathrm{~Pa}, \quad \rho 2300-3000 \mathrm{~kg} \mathrm{~m}^{-3}$ and height $1-20 \mathrm{~km}$ ) and the variation in this ratio for the four numerical experiments that include elastic material behaviour is of the same order (between 3 and 1867 using the elastic shear modulus, $\rho 1560 \mathrm{~kg} \mathrm{~m}^{-3}$, height $3.5 \mathrm{~km}$ ). However, in the set-up of our experiment, the viscous layer and the velocity discontinuity control the initial location of shear zones and this set-up is, therefore, not suitable for a systematic study of shear zone spacing.

The use of dynamic pressure in MohrCoulomb plasticity significantly increases the localization of deformation in shear zones (tests with I2ELVIS and Sopale, Fig. 9). A Von Mises model (no pressure dependence) with an equivalent strength and softening to the MohrCoulomb models shows a considerably lower degree of localization (Figs 9a and d). With a depth-dependent pressure (Fig. 9b) localization 
(g)
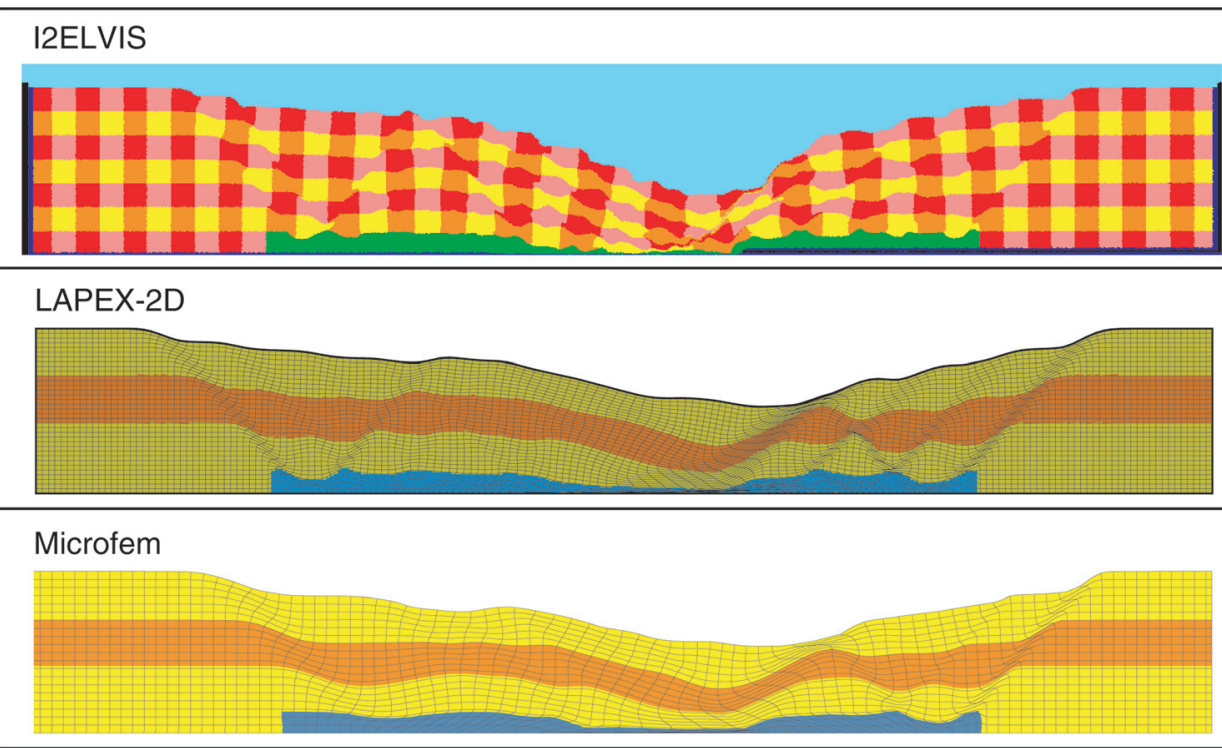

SloMo

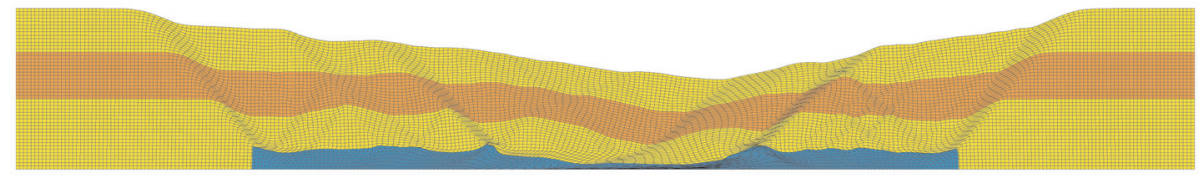

\section{Sopale}

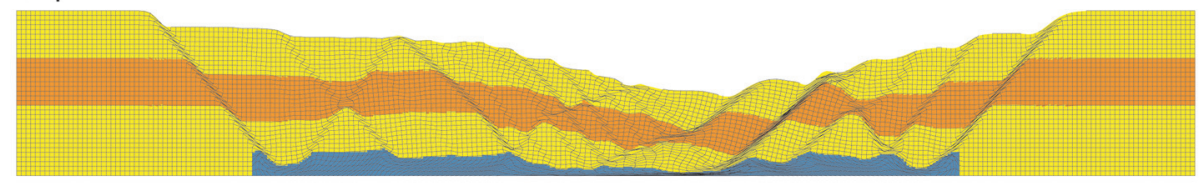

Analogue - Univ. Bern

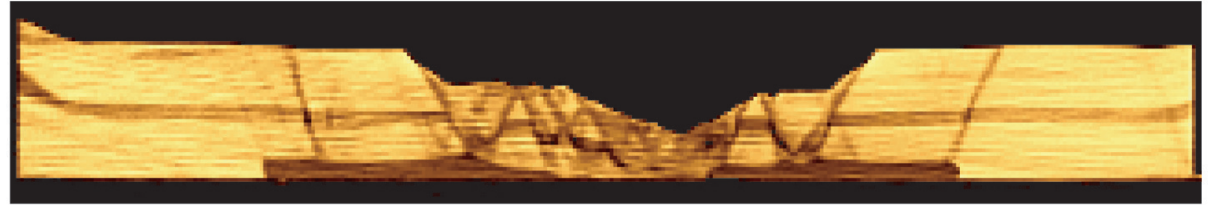

Analogue - IFP Rueil-Malmaison

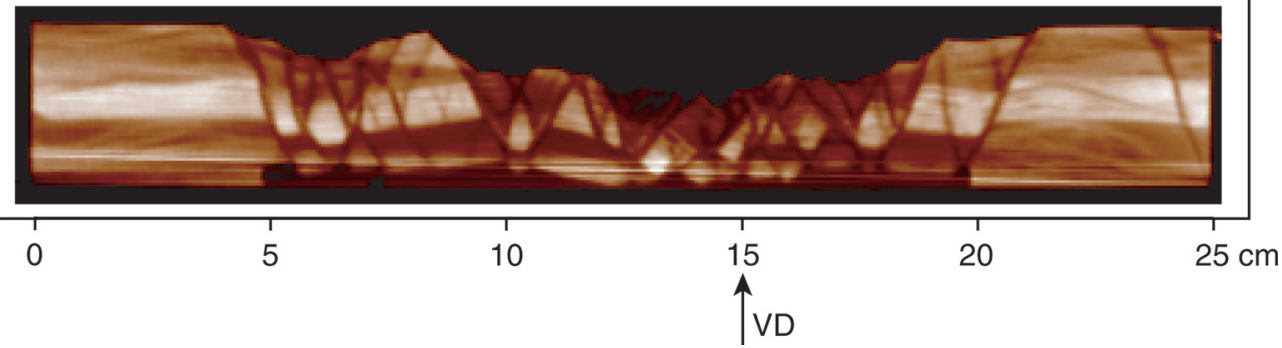

Fig. 7. Continued. 


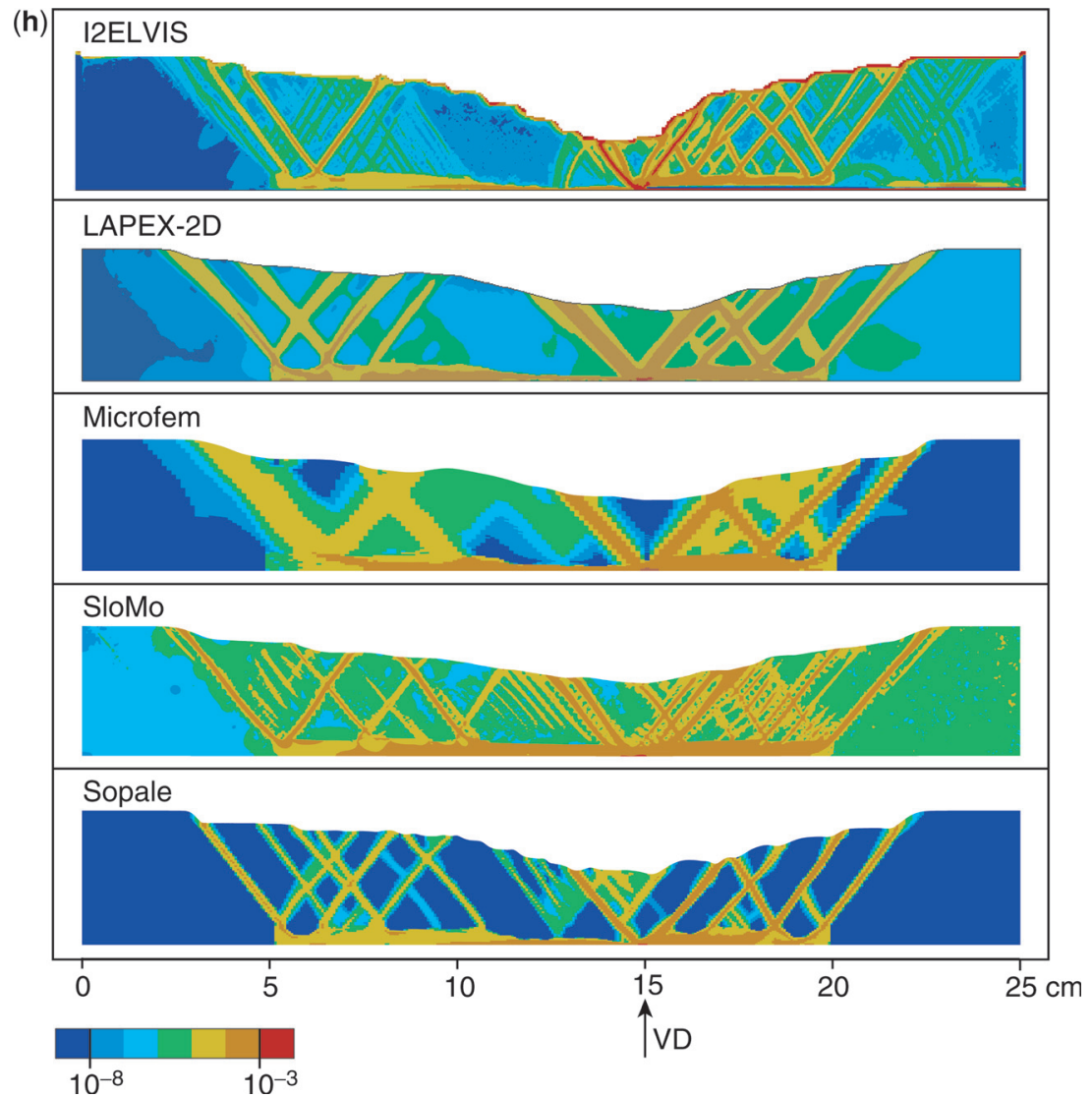

Fig. 7. Continued.

is still less than in the dynamic pressure case (Figs 9c and e). To be noted here is that the dynamic pressure is calculated differently in the two codes compared in Figure 9 (see also Figs $7 \mathrm{~d}$ and i). Sopale (and also Microfem) calculate dynamic pressure through a penalty formulation with a high but finite penalty ratio (Fullsack 1995) which leads to quasi-incompressibility (or a slight compressibility). In I2ELVIS the purely incompressible continuity equation is solved. Our test calculations with I2ELVIS have also shown that for a marker-in-cell technique, the numerical width of shear zones depends strongly on the interpolation schemes which are used for strain rate, stress and viscosity: numerical diffusion due to the interpolation between nodes of the grid and the markers can cause strong (two- to fivefold) widening of shear zones leading to a decrease in strain-rate contrast. Finite element and finite difference codes have a tendency to reduce shear zone width with decreasing element size, implying that numerical shear zone width is mesh-dependent. Very fine meshes probably underestimate the width of localized shear zones in comparison with observed shear band widths in granular media (see also de Borst \& Sluys 1991; Zervos et al. 2001).

\section{Sensitivity analyses}

In the extensional models presented here, two different boundary conditions were applied at the base. In Abaqus/Standard, I2ELVIS and Microfem, boundary friction was applied along the whole bottom boundary, including along the viscous material. In LAPEX-2D, SloMo and Sopale, grid points on the basal sheet were assigned the velocity with which the sheet was pulled and points to the left of the sheet were held fixed. The high level of agreement between the modelling results of the six experiments shows that any effect of this variation in basal boundary condition is small. The tip of 


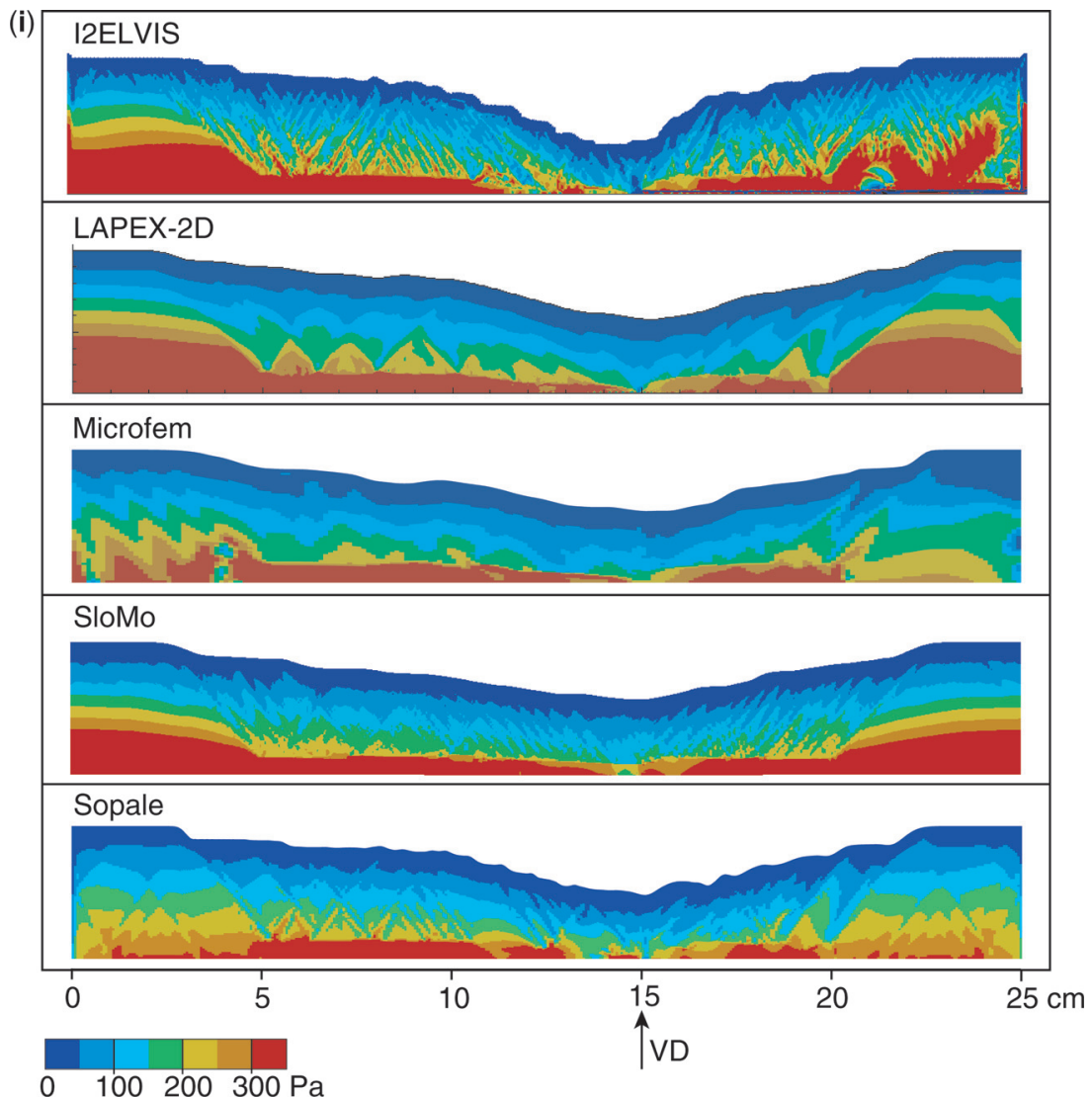

Fig. 7. Continued.

the basal sheet serves to initially localize deformation in a symmetric manner in the centre of the model. An experiment with a free slip base without basal sheet (run with Sopale) shows that in this case shear zones first form at the edges of the viscous layer and soon after in the centre of the model.

Experiments with I2ELVIS and Sopale show that a lower extensional velocity (which is equivalent to a lower viscosity for the viscous layer)

Table 5. Quantification of extension experiments*

\begin{tabular}{|c|c|c|c|c|c|c|c|}
\hline \multirow[t]{2}{*}{ Code } & \multirow[t]{2}{*}{$\begin{array}{c}\text { Fault ext. } \\
\text { at } 2 \mathrm{~cm}\end{array}$} & \multicolumn{2}{|c|}{$\begin{array}{l}\text { Fault initiation at } \\
\text { ends of PDMS }\end{array}$} & \multicolumn{2}{|c|}{$\begin{array}{c}\text { Fault on left side } \\
\text { of VD }\end{array}$} & \multicolumn{2}{|c|}{$\begin{array}{c}\text { Fault on right side } \\
\text { of VD }\end{array}$} \\
\hline & & Left & Right & dip & when & dip & when \\
\hline Abaqus/Standard & - & 0.5 & 0.5 & $45^{\circ}$ & 0 & $45^{\circ}$ & 0 \\
\hline I2ELVIS & $0.9-1.2$ & never & 2 & $51^{\circ}$ & 1 & $52^{\circ}$ & 1 \\
\hline LAPEX-2D & $0.7-0.9$ & 0.5 & 0.5 & $51^{\circ}$ & 0.5 & $53^{\circ}$ & 0.5 \\
\hline Microfem & $0.5-1.2$ & never & 1.5 & $46^{\circ}$ & 0.5 & $48^{\circ}$ & 0.5 \\
\hline SloMo & $0.7-0.8$ & 2 & 2 & $53^{\circ}$ & 1 & $55^{\circ}$ & 1 \\
\hline Sopale & $1.1-1.3$ & 0.5 & 0.5 & $50^{\circ}$ & 0.5 & $52^{\circ}$ & 0.5 \\
\hline Analogue ranges & $0.9-1.0$ & never & $2-4.5$ & $65^{\circ}-69^{\circ}$ & 0.5 & $60^{\circ}-65^{\circ}$ & 0.5 \\
\hline
\end{tabular}

${ }^{*}$ All values referred to sandbox scale in $\mathrm{cm}$. Output stages typically available at $0,0.5,1$ and then every $\mathrm{cm}$ of extension.

${ }^{\dagger}$ Fault-controlled horizontal extension determined by cut-off points between layers and the faults.

${ }^{\ddagger}$ Analogue values from experiments of University of Bern and IFP Rueil-Malmaison (Schreurs et al. 2006). 

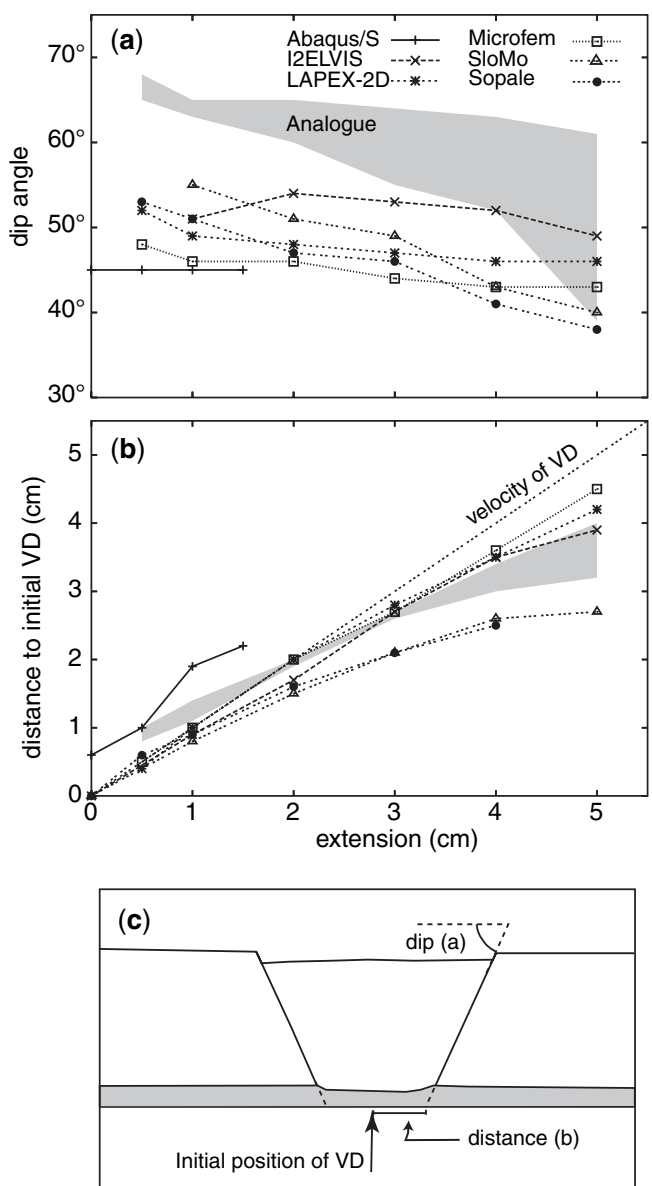

Fig. 8. (a) Dip angle of the first-formed normal fault on the right-hand side of the velocity discontinuity (the tip of the basal sheet) versus extension. (b) Migration of the same fault. The migration is measured relative to the initial position of the tip of the basal sheet. (c) Schematic drawing showing how the quantities in (a) and (b) were measured. The grey bands denote the range of values measured for the analogue experiments of University of Bern and IFP Rueil-Malmaison (see also Fig. 7 and Schreurs et al. 2006).

favours a more efficient outward propagation of shear zone development. The surface depression is less deep. A higher cohesion of the 'sand' material leads to locally steeper surface slopes, similar to our observations for the shortening experiment. We found that a reduction or increase in the strain softening range does not affect the results significantly. Tests with I2ELVIS and Sopale also showed that a higher resolution calculation grid (smaller element size) leads to the development of more shear zones which are better focussed, as discussed above. This can also be seen from a comparison of Microfem (lower resolution) to Sopale (higher resolution) results and is again similar to our observation for the shortening experiment.

\section{Implications of the numerical experiments}

Comparison between the different numerical codes for the extension experiment shows a high level of agreement. All predict the same location of maximum thinning and show the same general evolution and stepping out of shear zones. High-resolution numerical codes (e.g., Sopale) predict rotation of shear zones with larger finite deformation. The extensional results show much less variation compared to the shortening experiment. Ellis et al. (2004) suggest that experiments involving weak viscous layers reduce the influence of boundary conditions on both analogue and numerical results, and instead pass control to rheological strength contrasts within the model domain. In our set-up, the weak viscous basal layer serves to reduce the effect of stress discontinuities due to the basal velocity discontinuity.

Although the overall dynamics and evolution of the different numerical codes are similar, differences in the number of shear zones that develop, the timing at which the ends of the viscous layer are activated and the shear zone dip can be seen. These differences partly appear to reflect differences in mesh resolution. As for the shortening experiment, we find that caution is required in interpretations from numerical results involving number of shear zones and shear zone spacing.

Our numerical experiments may also have important implications for the understanding of pressure distributions in large-scale tectonic processes involving the development of shear zones. As follows from our results, the dynamic pressure field (Figs $7 \mathrm{~d}$ and i) in a medium subjected to brittle/plastic deformation deviates strongly from the lithostatic distribution often assumed in geosciences. These results are in line with other theoretical studies (e.g., Mancktelow 1995; Petrini \& Podladchikov 2001; Burg \& Gerya 2005) which predict significant underpressure and overpressure effects in orogenic processes. This, in turn, may have strong consequences for the pressure-temperature evolution of deformed rocks complexes composing the Earth's crust and lithospheric mantle. 


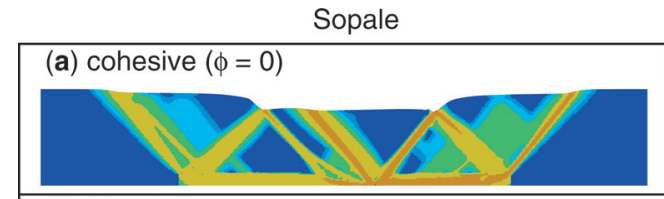

(b) lithostatic pressure

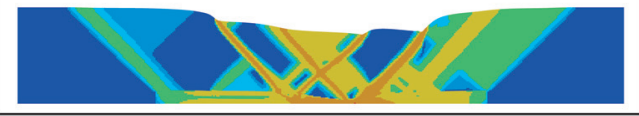

(c) dynamic pressure

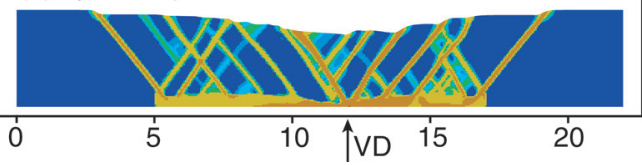

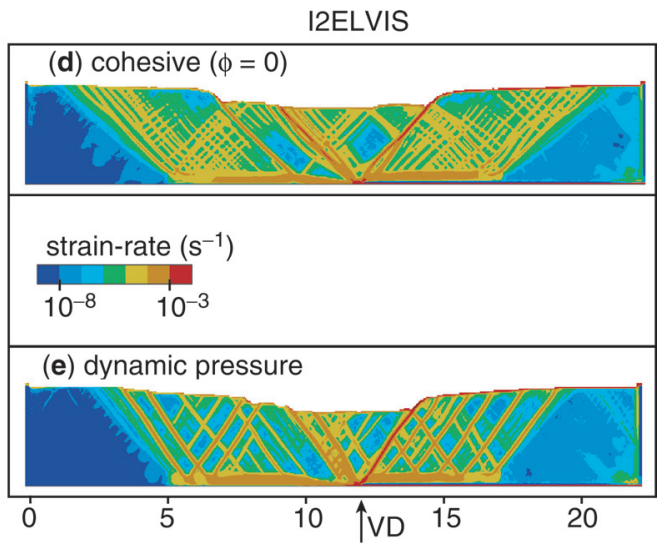

Fig. 9. A comparison of strain-rates for I2ELVIS and Sopale after $2 \mathrm{~cm}$ of extension shows the influence of the plasticity description. (a) and (d) Angle of internal friction $\phi=0$. Cohesion softens from $170 \mathrm{~Pa}$ to $140 \mathrm{~Pa}$ (sandbox scale). These values mimic the same strength and strength reduction as for the frictional extension models. (b) Sopale for Mohr-Coulomb plasticity with depth-dependent pressure. (c) and (e) Mohr-Coulomb plasticity with dynamic pressure (standard case).

\section{Comparison to analogue results}

Only two analogue experiments documented cross-sectional information at different extension stages and could be used to compare the numerical results against. The analogue results of the University of Bern and IFP Rueil-Malmaison show an overall similar evolution, but differ in the velocity with which normal faults are distributed outwards (Schreurs et al. 2006). The geometries of the numerical and analogue experiments after 1 and $5 \mathrm{~cm}$ of extension are shown in Figures $7 \mathrm{~b}$ and $\mathrm{g}$. The dip angle and migration of the first formed shear zone to the right of the velocity discontinuity are compared in Figure 8. In the numerical experiments reported here the mobile wall velocity is directly applied to the right-hand side of the models. However, in the analogue sandbox the role of the mobile wall is likely only to prevent the sand from collapsing and does not provide a driving force. The extension is passed to the model by the moving basal sheet. Because there is a sufficient distance between the right-hand wall and the velocity discontinuity this is, however, not likely to affect the analogue-numerical comparison.

Comparison of the numerical results to the two analogue experiments shows that: (1) The numerical experiments predict the overall dynamics and evolution of the analogue system reasonably well. (2) In both analogue and numerical results, shear zones initiate at the basal velocity discontinuity and with increasing extension new shear zones develop outwards. (3) Both numerical and analogue results show a rotation of shear zones with shallowing dip angles for increasing extension. (4) The velocity with which the first formed normal fault to the right of the velocity discontinuity moves to the right is very similar between the two analogue results and the numerical models (Fig. 8b). (5) The main difference between the analogue and numerical results is the dip angle of the shear zones (Figs 7 and 8a). The dip angles in the analogue experiments are much steeper (between $60^{\circ}$ and $69^{\circ}$ initially) and follow Coulomb behaviour, with dip angles predicted by $45^{\circ}+\phi / 2\left(63^{\circ}-68^{\circ}\right.$ for the material properties of the two analogue experiments). All numerical extension models assume zero dilation and for dynamic pressure-dependent Mohr-Coulomb behaviour dip angles between $45^{\circ}$ (Roscoe) and $45^{\circ}+\phi / 2$ (Coulomb) are then to be expected (Vermeer 1990) $\left(45^{\circ}-63^{\circ}\right.$ for our material properties). The observed initial dip angles $\left(45^{\circ}-55^{\circ}\right)$ are in the lower range of the theoretical values. Assigning a non-zero dilatation angle, $\psi$, to 'sand' will increase the theoretical minimum dip angle value to $45^{\circ}+\psi / 2$. Tests with I2ELVIS show that a non-zero dilatation angle indeed results in higher dip angles for the shear zones.

\section{The numerical sandbox}

Our study presents a direct qualitative and quantitative comparison of numerical and analogue model results for two experimental set-ups aimed at simulating upper-crustal tectonic processes. Results from seven numerical codes are compared to results from five analogue

\title{
WebColor
}

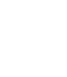


laboratories for a brittle thrust wedge experiment, while results from six numerical codes are compared to results from two analogue laboratories for a brittle-viscous extension experiment. The accompanying paper (Schreurs et al. 2006) shows additional analogue shortening and extension results, which could not be used in our comparison as either cross-sectional information was not recorded during the experiment or a different material (clay) was used.

A comparison of analogue experiments from different laboratories has to take into account that differences may occur in material properties (whereby properties may even slightly change due to storage conditions or small vibrations), modelling apparatus, model set-up (width and length) and in the set-up technique of individual experimenters. The effects of some variations can be tested by determining the reproducibility of each experiment in the same laboratory, but it is clearly of importance to determine the inter-laboratory reproducibility of analogue model results as well. The accompanying paper (Schreurs et al. 2006) shows an encouraging first order agreement of model results of different analogue laboratories, despite variability in model widths and in material properties.

In comparison, numerical experiments have the potential to be much more reproducible, since material properties, model set-up and boundary conditions can be specified exactly. However, set-ups between different experimenters may also vary in subtle ways depending on assumptions used, and even slightly different ways of interpreting and prescribing the initial set-up. The eight numerical codes used in our comparison differ with each other for the following properties and assumptions: (1) resolution, imposed element aspect ratios, and type of element; (2) time step (extension experiment); (3) smoothing of velocity discontinuities; (4) implementation of frictional boundaries; (5) material properties (dilatation and elasticity); (6) scaling; (7) calculation of dynamic pressure; and (8) surface smoothing (shortening experiment). Our results indicate that grid resolution, representation of boundary conditions (boundary friction and velocity discontinuities), calculation of dynamic pressure and dilatation require careful attention in sandbox-type experiments. In contrast, elastic material behaviour, scaling of the experiment and small amounts of surface smoothing appear to play only a minor role.

Our results highlight that different numerical solution methods (finite difference method, finite element method, distinct element method) can successfully be used to reproduce structures seen in analogue sandbox models. The numerical codes can do reasonably well in qualitatively predicting the dynamic evolution of the system in shortening and extension, shear zone (fault) formation, and taper geometry (shortening experiment). The level of variability between the numerical results is about the same as the degree of variability between the analogue results. Numerical codes show differences with each other, and the analogue experiments, for detailed location, dip and spacing of shear zones. As the initial set-up and material properties of analogue models can be relatively well constrained, their results can form a useful test for numerical models. Numerical models may, therefore, benefit from future studies focusing on the differences between analogue and numerical modelling results. Our results indicate that future experiments should preferably choose a simplified set-up that reduces the effects of boundary conditions and especially abrupt changes in boundary velocities, prescribe resolution and time step size, use material behaviour which is as similar as possible and, if possible, quantify results in an unambiguous manner.

Our results emphasize the importance of the following issues for numerical sandbox-type studies: (1) the ability to model large deformation structures; (2) the ability to represent boundary friction, velocity discontinuities and a free surface; (3) the representation of a composite (elasto)-visco-plastic rheology; (4) calculation with a relatively high resolution (important for shear zone evolution, for example); (5) minimization of numerical diffusion; and (6) consensus on the procedure for quantification of the results. These are important for studies in which numerical and analogue models are used in combination, but reflect at the same time the requirement to study Earth tectonic processes.

\section{Conclusions}

Two experimental set-ups inspired by settings from structural geology were used to compare eight numerical codes to each other. Despite differences in set-up and material behaviour between the individual experiments, the results are useful in showing that: (1) Numerical codes at the present time are capable of modelling the dynamic evolution of compressional and extensional settings, including shear-zone development, forward propagation of thrust wedges, and taper geometry of convergent wedges. The qualitative behaviour of the different codes is similar. (2) A quantitative analysis of the results of these codes shows a higher degree of variability, particularly in number of shear 
zones that develop and their spacing and dip angle. (3) A comparison between the results of the numerical codes and equivalent analogue experiments shows agreement in the overall evolution of the system and in the localization of deformation onto faults/shear zones. The variability among the numerical results is of the same order as the variations among the analogue results. Differences with the analogue results are also apparent, for example, in dip angles of extensional shear zones, degree of localization, and the development of backthrusts in the shortening experiment. Reducing these differences represents an interesting challenge for numerical modellers.

We hope that the comparisons shown here are a useful guide to the structural geology community, in highlighting the degree to which numerical codes may be used to reproduce experiments in the sandbox and/or processes at the scale of the upper crust.

The figures of the analogue experiments were kindly provided by the laboratories of Bern (GS), IFP Rueil Malmaison (J.-M. Daniel, J.-M. Mengus), Parma (E. Costa, C. Cavozzi), Pavia (A. Ravaglia) and Toronto (D. Boutilier, A. Cruden). J. Lohrmann measured the angle of friction of (GFZ Potsdam) sand on 'Alkor' foil. C. Beaumont, J.-P. Brun and B. Colletta gave us helpful feedback on the design of the experiments. We thank the participants of the GeoMod2004 pre-conference workshop for their insightful discussions and Claudio Faccenna for sharing with us his introductory talk on analogue and numerical modelling which he presented at this workshop. We would like to thank N. Kukowski and the reviewers R. Buck and K. Furlong for their positive feedback, and Y. Podladchikov, S. Hoth and S. Medvedev for stimulating discussions. Microfem and Sopale were developed by P. Fullsack and the Geodynamics Group at Dalhousie University. Simulations by BK have been run at the USC high performance computing facilities. This work was supported by ETH Research Grant TH-12/04-1, RFBR grant \#03-05-64633 and the RF President Program 'Leading Scientific School of Russia' (grant \#03.5.1645) to TVG and project SFB-267 from the Deutsche Forschungsgemeinschaft for AYuB and AK.

\section{References}

Q2.2 Abaqus/Standard User's Manual 2003. Vol. 1 \& 2, version 6.4. Abaqus Inc, Pawtucket, Rhode Island, USA.

ADAM, J. \& URAI, J. L. ET AL. 2005. Shear localization and strain distribution during tectonic faulting new insights from granular-flow experiments and high-resolution optical image correlation techniques. Journal of Structural Geology, 27, 283-301.

Babeyko, A. Yu., Sobolev, S. V., Trumbull, R. B., Oncken, O. \& LAVIER, L. L. 2002. Numerical models of crustal scale convection and partial melting beneath the Altiplano-Puna Plateau. Earth and Planetary Science Letters, 199, 373-388.

Bahroudi, A., Koyi, H. A. \& Talbot, C. J. 2003. Effect of ductile and frictional décollements on style of extension. Journal of Structural Geology, 25, 1401-1423.

Behn, M. D., Lin, J. \& Zuber, M. T. 2002. A continuum mechanics model for normal faulting using a strain-rate softening rheology: implications for thermal and rheological controls on continental and oceanic rifting. Earth and Planetary Science Letters, 202, 725-740.

Blankenbach, B. \& Busse, F. ET AL. 1989. A benchmark comparison for mantle convection codes. Geophysical Journal International, 98, 23-38.

Burbidge, D. R. \& Braun, J. 2002. Numerical models of the evolution of accretionary wedges and fold-and-thrust belts using the distinctelement method. Geophysical Journal International, 148, 542-561.

BURG, J.-P. \& GERYA, T. V. 2005. Viscous heating and thermal doming in orogenic metamorphism: numerical modelling and geological implications. Journal of Metamorphic Geology, 23, 75-95.

Cruden, A. R., Nasseri, M. B. \& Pysklywec, R. 2006. Surface topography and internal strain variation in wide hot orogens from threedimensional analogue and two-dimensional numerical vise models. In: Buiter, S. J. H. \& Schreurs, G. (eds) Analogue and Numerical Modelling of Crustal-Scale Processes. Geological Society, London, Special Publications, 253, xx-yy.

Cundall, P. A. 1990. Numerical modelling of jointed and faulted rock. In: Rossmanith, A. (ed.) Mechanics of Jointed and Faulted rocks. Balkema, Rotterdam, 11-18.

Cundall, P. A. \& Board, M. 1988. A microcomputer program for modelling large-strain plasticity problems. In: Swoboda, G. (ed.) 6th International Conference in Numerical Methods in Geomechanics. A. A. Balkema, Brookfield, VT, 2101-2108.

Cundall, P. A. \& Strack, D. L. 1979. A discrete numerical model for granular assemblies. Geotechnique, 29, 47-65.

Cuvelier, C., Segal, A. \& van Steenhoven, A. A. 1986. Finite Element Methods and Navier-Stokes Equations. Reidel Publishing Company, Dordrecht, 483pp.

Dahlen, F. A. 1984. Noncohesive critical Coulomb wedges: an exact solution. Journal of Geophysical Research, 89, 10, 125-10, 133.

Davis, D., Suppe, J. \& Dahlen, A. 1983. Mechanics of fold-and-thrust belts and accretionary wedges. Journal of Geophysical Research, 88, 1153-1172.

DE Borst, R. \& SLuYs, L. J. 1991. Localization in a Cosserat continuum under static and dynamic loading conditions. Computer Methods in Applied Mechanics and Engineering, 90, 805-827.

Ellis, S., Schreurs, G. \& Panien, M. 2004. Comparisons between analogue and numerical models of thrust wedge development. Journal of Structural Geology, 26, 1659-1675. 
FULLSACK, P. 1995. An arbitrary Lagrangian-Eulerian formulation for creeping flows and its application in tectonic models. Geophysical Journal International, 120, 1-23.

Gerya, T. V. \& Yuen, D. A. 2003. Characteristicsbased marker-in-cell method with conservative finite-difference schemes for modelling geological flows with strongly variable transport properties. Physics of the Earth and Planetary Interiors, 140, 293-318.

Gutscher, M.-A., KuKowski, N., Malavieille, J. \& LALlEMAND, S. 1998a. Material transer in accretionary wedges from analysis of a systematic series of analog experiments. Journal of Structural Geology, 20, 407-416.

Gutscher, M.-A., Kukowski, N., Malavieille, J. \& LALlEMAND, S. 1998b. Episodic imbricate thrusting and underthrusting: Analog experiments and mechanical analysis applied to the Alaskan Accretionary Wedge. Journal of Geophysical Research, 103, 10, 161-10, 176.

HubBert, M. K. 1937. Theory of scale models as applied to the study of geologic structures. Bulletin of the Geological Society of America, 48, $1459-1520$.

JAEger, J. C. \& CoOK, N. G. W. 1979. Fundamentals of Rock Mechanics. John Wiley and Sons, New York, 585pp.

KaUs, B. J. P. 2005. Modelling approaches to geodynamic processes. $\mathrm{PhD}$ thesis, ETH Zürich. Le Pourhiet, L., Mattioni, L. \& Moretti, I. 2006 3D modelling of rifting through a pre-existing stack of nappes in the Gulf of Corinth (Greece): a mixed analogue/numerical approach. In: BUITER, S. J. H. \& Schreurs, G. (eds) Analogue and Numerical Modelling of Crustal-Scale Processes. Geological Society, London, Special Publications, 253, xx-yy.

LOHRMANN, J., KuKOwSKi, N., ADAM, J. \& ONCKEN, O. 2003. The impact of analogue material properties on the geometry, kinematics, and dynamics of convergent sand wedges. Journal of Structural Geology, 25, 1691-1771.

ManckTelow, N. S. 1995. Nonlithostatic pressure during sediment subduction and the development and exhumation of high pressure metamorphic rocks. Journal of Geophysical Research, $\mathbf{1 0 0}$, 571-583.

Michon, L. \& Merle, O. 2000. Crustal structures of the Rhine graben and the Massif Central grabens: An experimental approach. Tectonics, 19(5), 896-904

Mulugeta, G. 1988. Modelling the geometry of Coulomb thrust wedges. Journal of Structural Geology, 10, 847-859.

Mulugeta, G. \& Koyi, H. 1992. Episodic accretion and strain partitioning in a model sand wedge. Tectonophysics, 202, 319-333.

NISA II ${ }^{\mathrm{TM}}$ User's Manual Version 7.0, 1997. Engineering Mechanics Research Corporation, Troy, Michigan, USA.

PANIEN, M. 2004. Analogue modelling experiments of basin inversion using well-characterized granular materials and comparisons with numerical models. Ph.D. thesis. University of Bern, Switzerland.

Panien, M., Buiter, S. J. H., Schreurs, G. \& PFIFFNER, O. A. 2006. Inversion of a symmetric basin: Insights from a comparison between analogue and numerical experiments. In: BUITER, S. J. H. \& Schreurs, G. (eds) Analogue and Numerical Modelling of Crustal-Scale Processes. Geological Society, London, Special Publications, 253, xx-yy.

Pelletier, D., Fortin, A. \& Camarero, R. 1989. Are FEM solutions of incompressible flows really incompressible? (Or how simple flows can cause headaches!) International Journal of Numerical Methods in Fluids, 9, 99-112.

Petrini, K. \& Podladchikov, Y. 2000. Lithospheric pressure-depth relationship in compressive regions of thickened crust. Journal of Metamorphic Geology, 18, 67-77.

$\mathrm{PFC}^{2 \mathrm{D}}$ USER's GUIDE 1999. Version 3.0. Itasca Consulting Group, Inc.

Poliakov, A. N. \& Podladchikov, Y. Y. 1992. Diapirism and topography. Geophysical Journal International, 109, 553-564.

Poliakov, A. N., Cundall, P. A., Podladchikov, Y. Y. \& LyAKHOVsKy, V. A. 1993. An explicit inertial method for the simulation of the viscoelastic flow: an evaluation of elastic effects on diapiric flow in two- and three-layers models. In: Stone, D. B. \& Runcorn, S. K. (eds) Flow and Creep in the Solar System: Observations, Modelling and Theory. Kluwer Academic Publishers, $175-195$.

RANALLI, G. 1987. Rheology of the Earth: deformation and flow processes in geophysics and geodynamics. Allen \& Unwin Inc., Winchester, USA, 366pp.

Saltzer, S. D. \& Pollard, D. D. 1992. Distinct element modelling of structures formed in sedimentary overburden by extensional reactivation of basement normal faults. Tectonics, 11(1), $165-174$.

Sassi, W., Colletta, B., Balé, P. \& Paquereau, T. 1993. Modelling of structural complexity in sedimentary basins: the role of pre-existing faults in thrust tectonics. Tectonophysics, 226, 97-112.

Schellart, W. P. 2000. Shear test results for cohesion and friction coefficients for different granular materials: scaling implications for their usage in analogue modelling. Tectonophysics, 324, 1-16.

Schreurs, G. \& Buiter, S. J. H. ETAL. 2006. Analogue benchmarks of shortening and extension experiments. In: Buiter, S. J. H. \& SChreurs, G. (eds) Analogue and Numerical Modelling of CrustalScale Processes. Geological Society, London, Special Publications, 253, xx-yy.

Smart, K. J. \& Couzens-Schulz, B. A. 2001. Mechanics of blind thrusting: Comparison of numerical and physical modelling. The Journal of Geology, 109, $771-779$.

Storti, F., Salvini, F. \& McClay, K. 2000. Synchronous and velocity-partitioned thrusting and thrust polarity reversal in experimentally produced, doubly-vergent thrust wedges: Implications for natural orogens. Tectonics, 19(2), 378-396. 
Strayer, L. M., Hudleston, P. J. \& Lorig, L. J. 2001. A numerical model of deformation and fluid-flow in an evolving thrust wedge. Tectonophysics, 335, 121-145.

Vanbrabant, Y., Jongmans, D., Hassani, R. \& BELLINO, D. 1999. An application of twodimensional finite-element modelling for studying the deformation of the Variscan fold-and-thrust belt (Belgium). Tectonophysics, 309, 141-159.

van Keken, P. E., King, S. D., Schmeling, H., Christensen, U. R., Neumeister, D. \& DoIN, M.-P. 1997. A comparison of methods for the modelling of thermochemical convection. Journal of Geophysical Research, 102, 22, 477-22, 495.

Vermeer, P. A. 1990. The orientation of shear bands in biaxial tests. Geotechnique, 40, 223-236.
Weijermars, R. 1986. Flow behaviour and physical chemistry of bouncing putties and related polymers in view of tectonic laboratory applications. Tectonophysics, 124, 325-358.

Wijns, C., Boschetti, F. \& Moresi, L. 2003. Inverse modelling in geology by interactive evolutionary computation. Journal of Structural Geology, 25, 1615-1621.

Zervos, A., Papanastasiou, P. \& Vardoulakis, I. 2001. A finite element displacement formulation for gradient plasticity. International Journal for Numerical Methods in Engineering, 50, 1369-1388.

Zhao, W.-L., Davis, D. M., Dahlen, F. A. \& Suppe, J. 1986. Origin of convex accretionary wedges: evidence from Barbados. Journal of Geophysical Research, 91, 10246-10258. 